\title{
Reformulating atmospheric aerosol thermodynamics and hygroscopic growth into fog, haze and clouds
}

\author{
S. Metzger and J. Lelieveld \\ Max Planck Institute for Chemistry, Mainz, Germany \\ Received: 30 November 2006 - Published in Atmos. Chem. Phys. Discuss.: 18 January 2007 \\ Revised: 29 May 2007 - Accepted: 1 June 2007 - Published: 20 June 2007
}

\begin{abstract}
Modeling atmospheric aerosol and cloud microphysics is rather complex, even if chemical and thermodynamical equilibrium is assumed. We show, however, that the thermodynamics can be considerably simplified by reformulating equilibrium to consistently include water, and transform laboratory-based concepts to atmospheric conditions. We generalize the thermodynamic principles that explain hydration and osmosis - merely based on solute solubilities - to explicitly account for the water mass consumed by hydration. As a result, in chemical and thermodynamical equilibrium the relative humidity $(\mathrm{RH})$ suffices to determine the saturation molality, including solute and solvent activities (and activity coefficients), since the water content is fixed by RH for a given aerosol concentration and type. As a consequence, gas/liquid/solid aerosol equilibrium partitioning can be solved analytically and non-iteratively. Our new concept enables an efficient and accurate calculation of the aerosol water mass and directly links the aerosol hygroscopic growth to fog, haze and cloud formation.

We apply our new concept in the 3rd Equilibrium Simplified Aerosol Model (EQSAM3) for use in regional and global chemistry-transport and climate models. Its input is limited to the species' solubilities from which a newly introduced stoichiometric coefficient for water is derived. Analogously, we introduce effective stoichiometric coefficients for the solutes to account for complete or incomplete dissociation. We show that these coefficients can be assumed constant over the entire activity range and calculated for various inorganic, organic and non-electrolyte compounds, including alcohols, sugars and dissolved gases. EQSAM3 calculates the aerosol composition and gas/liquid/solid partitioning of mixed inorganic/organic multicomponent solutions and the associated water uptake for almost 100 major compounds. It explicitly accounts for particle hygroscopic growth by
\end{abstract}

Correspondence to: S. Metzger

(metzger@mpch-mainz.mpg.de) computing aerosol properties such as single solute molalities, molal based activities, including activity coefficients for volatile compounds, efflorescence and deliquescence relative humidities of single solute and mixed solutions. Various applications and a model inter-comparison indicate that a) the application is not limited to dilute binary solutions, b) sensitive aerosol properties such as hygroscopic growth and the $\mathrm{pH}$ of binary and mixed inorganic/organic salt solutions up to saturation can be computed accurately, and c) aerosol water is central in modeling atmospheric chemistry, visibility, weather and climate.

\section{Introduction}

It is widely acknowledged that atmospheric aerosol particles affect human and ecosystem health, clouds and climate (e.g. EPA, 1996; Holgate et al., 1999; Seinfeld and Pandis, 1998; IPCC, 2007). However, it is less well recognized that gas/liquid/solid partitioning of atmospheric particles and precursor gases largely determine the composition and hygroscopicity of the aerosols, which in turn govern the size distribution, the atmospheric lifetime of both the particles and the interacting gases, and the particle optical properties. For instance, sea salt particles can deliquesce at a very low relative humidity $(\mathrm{RH})$ of $\sim 32 \%$ since they contain a small amount of the very hygroscopic salt magnesium chloride $\left(\mathrm{MgCl}_{2}\right)$. Therefore, marine air is often much hazier than continental air at the same ambient temperature $(T)$ and $\mathrm{RH}$.

Overall, the most abundant aerosol species is water. For a given $T$ and RH aerosol water determines the phase partitioning between the gas-liquid-solid and ice phases and the composition of atmospheric aerosols due to changes in the vapor pressure above the particle surface (Pruppacher and Klett, 1997). The hygroscopic growth of the aerosol particles influences heterogeneous reactions, light extinction and visibility, whereby aerosol water is most relevant for the direct

Published by Copernicus Publications on behalf of the European Geosciences Union. 
radiative forcing of Earth's climate (Pilinis et al., 1995). However, aerosol water depends, besides the meteorological conditions, on the ionic composition of the particles, which in turn depends on the aerosol water mass. Consequently, gas-aerosol partitioning and aerosol water mass are difficult to measure or predict numerically (by established methods), even if the complex gas-aerosol system is simplified by assuming thermodynamic gas/liquid/solid aerosol equilibrium (Seinfeld and Pandis, 1998, and references therein).

The underlying principles that govern the gas-aerosol equilibrium partitioning and hygroscopic growth have been formulated toward the end of the nineteenth century by Gibbs (1839-1903), the architect of equilibrium thermodynamics. Most of our current understanding of equilibrium, which follows from the second law of thermodynamics, derives from Gibbs (1876). Among the numerous publications that have appeared since, none has consistently transformed the basic principles of equilibrium thermodynamics to atmospheric aerosol modeling applications.

The problem is twofold: (a) the amount of water mass consumed by hydration is not explicitly accounted for although hydration drives the hygroscopic growth of natural and manmade aerosols, and (b) the water mass used to define the aerosol activity coefficients is kept constant, which is reasonable for laboratory but not for atmospheric conditions thus leading to a conceptual difficulty.

Here we overcome these problems by introducing a new approach for the calculation of the aerosol hygroscopic growth and the subsequent water uptake into fog, haze and clouds, which has several advantages. First, the complex system of the gas/liquid/solid aerosol equilibrium partitioning can be solved analytically, which limits computational requirements. Second, a large number of aerosol physicalchemical properties can be directly and explicitly computed. This includes aerosol activities (and activity coefficients), the water activity (with or without the Kelvin term), single solute molalities of binary and mixed solutions of pure inorganic or mixed inorganic/organic compounds, efflorescence and deliquescence RHs of soluble salt compounds (binary and mixed solutions), and related optical properties, so that subsequently all relevant aerosol properties such as dry and ambient radii, mass and number distribution can be directly derived at a given RH and $T$.

Third, our new concept allows to consistently and efficiently link aerosol thermodynamics and cloud microphysics through explicit computation of the aerosol water mass, from which the initial cloud water/ice mass, cloud droplet/ice number concentrations, and the cloud cover can be calculated. Fourth, the explicit account for the water mass consumed by hydration can be directly connected to aerosol chemical composition and emission sources, being characterized by a certain mix of compounds that can undergo atmospheric chemistry.

Thus, our method allows to explicitly link emissions to atmospheric conditions, including visibility reduction and climate forcing through anthropogenic activities. This not only helps to abandon the use of ambiguous terms such as "marine" and "continental" aerosols, it also allows to refine lumped categories such as mineral dust, biomass burning, sea salt, organic and sulfate aerosols currently used in atmospheric modeling. Consequently, our method is more explicit than the traditional concept of cloud condensation nuclei (CCN), which relies on activation thresholds that do not explicitly relate the particle chemical composition to droplet formation.

In Sect. 2 we generalize the basic thermodynamic principles of hydration and osmosis and translate them to atmospheric conditions. In Sect. 3 we introduce new formulations required to consistently calculate the activity (including solute molalities and activity coefficients) and the water mass of atmospheric aerosols, and we demonstrate how the aerosol and cloud thermodynamics can be directly coupled by reformulating chemical equilibrium to consistently include water. In Sect. 4 we apply our new approach in a new version (3) of the EQuilibrium Simplified Aerosol Model (EQSAM3), and present results of a model inter-comparison. The new aspects and limitations of our new approach are discussed in Sect. 5, and we conclude with Sect. 6 . The appendix includes tables of acronyms, abbreviations and symbols used in this study.

In an electronic supplement (http://www.atmos-chem-phys.net/7/3163/2007/ acp-7-3163-2007-supplement.zip), we provide (1) additional figures of single solute molalities and the associated water uptake for all compounds listed in Table 1 (complementing Fig. 2a and b), including a list of compounds, and (2) the derivation of the standard definitions of the "classical" equilibrium thermodynamics (e.g. Denbigh, 1981; Seinfeld and Pandis, 1998; Wexler and Potukuchi, 1998).

\section{Revisiting thermodynamic principles}

We refer to "classical" equilibrium thermodynamics, since water is generally omitted in equilibrium equations unless explicitly involved in the reaction, based on the assumption that water is neither consumed nor produced. However, when hydration is involved, water is consumed and released, which causes inconsistencies in the standard treatment.

Furthermore, equilibrium thermodynamics of atmospheric aerosols have - thus far - been defined for laboratory conditions and subsequently applied to atmospheric modeling. This introduces a conceptual difficulty, in particular for laboratory based activity coefficients, which are central in aerosol thermodynamics. In the laboratory the water mass is usually held constant to measure aerosol activity and activity coefficients as a function of solute concentration.

In contrast to the laboratory, condensed water in the atmosphere is not a constant. At equilibrium, the aerosol water is proportional to the solute concentration. More soluble 
(hygroscopic) particles take up more water from the atmosphere for solute hydration, since each particle solution will become saturated at equilibrium (per definition). An increase in solute concentration (e.g. due to condensation of volatile compounds, coagulation, or chemical reactions) therefore either leads to additional water uptake, or to solute precipitation (causing a solid phase to co-exists with the aqueous phase), while a decrease of the solute concentration (e.g. due to evaporational loss or chemical reactions) would be associated with the evaporation of aerosol water, so that finally, when equilibrium is reached again, the aerosol molality remains constant at a given RH and $T$.

The available water mass for condensation depends primarily on the available water vapor $\left(P_{w}[P a]\right)$, and the temperature dependent saturation vapor pressure $\left(P_{w \text {,sat }}[P a]\right)$; the ratio defines the relative humidity $\left(\mathrm{RH}=P_{w} / P_{w \text {, sat }}\right)$. However, the aerosol water mass depends for a given amount of solute also on the hygroscopicity of the solute; hygroscopicity is the ability to absorb (release) water vapor from (to) the surrounding atmosphere. In particular the ability of salt solutes to hydrate causes hygroscopic growth of aerosol particles at subsaturated atmospheric conditions $(\mathrm{RH}<1)$, where the equilibrium water uptake of atmospheric aerosols is generally limited by the available water vapor mass (respective $\left.P_{w}\right)$.

Instead, near saturation or at supersaturation the hygroscopic growth of aerosol particles continues and yields cloud droplets, whereby the water uptake at $\mathrm{RH} \geq 1$ is only limited by the temperature dependent saturation water vapor mass. Excess water vapor directly condenses into cloud droplets/crystals, and with limited water vapor available larger particles ultimately grow mainly dynamically at the expense of smaller particles, since their ability to collect water is largest (either due to their larger cross-sections or fall velocities).

In either case $(\mathrm{RH}<1$ and $\mathrm{RH} \geq 1)$ the water uptake is determined by the amount and type of solutes. The water associated with a certain amount and type of solute can be obtained from water activity measurements in the laboratory (e.g. Tang and Munkelwitz, 1994), or directly calculated from the vapor pressure reduction that occurs after dissolving a salt solute in water - well-known as Raoult's law (Raoult, 1888) - if solution non-idealities are taken into account (Warneck, 1988; Pruppacher and Klett, 1997). Note Raoult's law characterizes the solvent, Henry's law the solute.

However, in the atmosphere at equilibrium conditions, where evaporation balances condensation, the vapor pressure reduction is fully compensated by the associated water uptake, so that the equilibrium growth of aerosol particles can be directly approximated as a function of relative humidity (Metzger, 2000; Metzger, et al., 2002a). Nevertheless, no general concept yet exists, despite the various efforts to predict the hygroscopic growth of atmospheric aerosols (Köhler, 1936; Zadanovskii, 1948; Robinson and Stokes, 1965; Stokes and Robinson, 1966; Low, 1969; Hänel,
1970; Winkler, 1973; Fitzgerald, 1975; Hänel, 1976; Winkler, 1988; for a more general overview see e.g. the textbooks of Pruppacher and Klett, 1997; Seinfeld and Pandis, 1998; and references therein).

We therefore introduce in the following a new approach that describes (a) the water uptake not only as a function of relative humidity for various inorganic and organic salt compounds found in natural or man-made pollution aerosols, but also (b) explicitly accounts for the water mass consumed by hydration (Sect. 2.2), upon (c) considering the required transformation to atmospheric conditions (Sect. 2.3).

Our new approach generalizes hydration and osmosis according to standard chemical methods, by accounting for a stoichiometric constant for water (Sect. 2.2.1), which can be derived for any compound based on the measured or estimated solubility (Sect. 3.4). This new stoichiometric constant for water is introduced in analogy to the stoichiometric constants of the solutes. For the latter we use effective ones to account for incomplete dissociation of certain solutes (e.g. weak electrolytes, or non-electrolytes). New formulas will also be derived in Sect. 3.5, 3.6, 3.7 to analytically (noniteratively) predict for a given $\mathrm{RH}$ and $T$ the aerosol molality, efflorescence and deliquescence RHs, and the aerosol water mass associated with major inorganic and organic salt compounds and their mixtures, including various non-electrolyte compounds such as sugars, alcohols or dissolved gases.

\subsection{Laboratory conditions}

\subsubsection{Osmosis}

In general, the nature of hygroscopic growth of solutes is best understood by using an osmotic system, represented by one solution separated from another by a semi-permeable membrane, as illustrated in Fig. 1a. Osmosis, first investigated by Pfeffer (1881), describes the net flow of water through the membrane driven by a difference in solute concentrations, which results in an osmotic pressure (turgor). The size of the membrane pores is large enough to separate small molecules (e.g. water or small ions) from larger ones (e.g. hydrated sodium and chloride ions).

Osmosis produces a pressure on a membrane, П $[\mathrm{Pa}]$ ), which depends primarily on the concentration of the solute, though also on its nature. Adding a salt solute (e.g. 1 mole of sodium chloride $(\mathrm{NaCl})$ to the left compartment of Fig. 1a) develops an osmotic pressure due to the additional volume occupied by the hydrated solute. Depending on the nature of the solute - in particular its chemical bond strengths - the salt solute can dissociate, thus occupying more volume. If the volume expands in height, a hydrostatic pressure builds up, which can be regarded as an osmotic counter pressure (Fig. 1a). The associated decrease of the partial vapor pressure of either solute or solvent above the solution allows to measure the osmotic pressure quantitatively from the resulting pressure differences above the two compartments. For 


\section{Osmosis - Pfeffer cell}

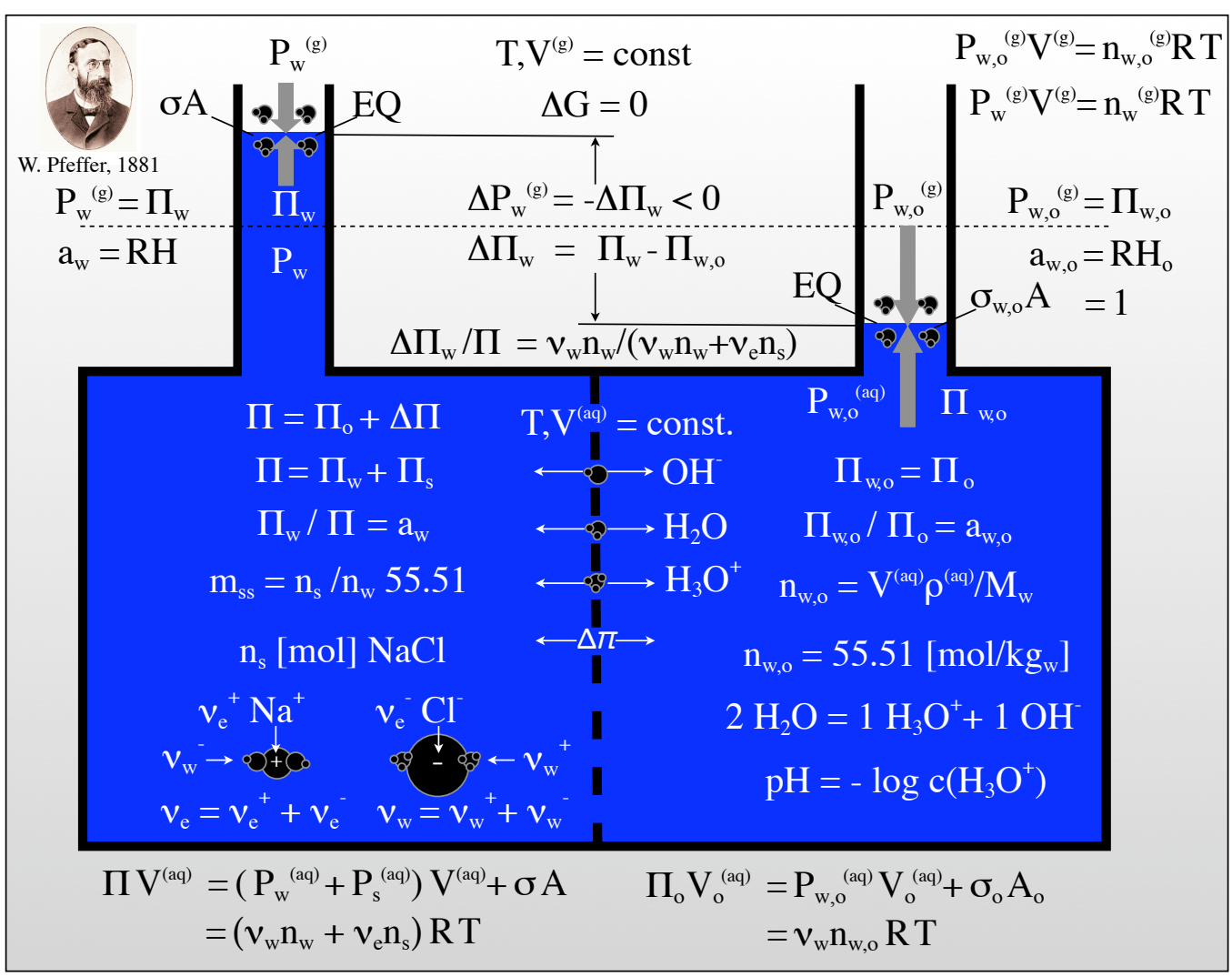

Fig. 1a. Laboratory conditions: schematic of an osmotic system.

instance, the total change in partial pressures yields for water $\Delta P_{w}^{(\mathrm{g})}=P_{w}^{(\mathrm{g})}-P_{w, o}^{(\mathrm{g})}$. This change is primarily a measure of the solute's concentration, but also measures the solute's hygroscopicity if the amount of water consumed by hydration per mole of solute is explicitly accounted for.

In equilibrium, evaporation and condensation of water molecules above each surface balances (Fig. 1a), so that $\Delta P_{w}^{(\mathrm{g})}$ adjusts to a maximum, equal to the total change of the osmotic pressure of water, though with opposite sign $\left(\Delta P_{w}^{(\mathrm{g})}=-\Delta \Pi_{w}\right)$. Although the magnitude of a molar pressure change is characteristic for the solute, different solutes that occupy the same volume cause the same osmotic pressure (change). Note that we consider changes, since both compartments may contain solutes. We further consider that the osmotic pressure change $\Delta \Pi$ includes a change that results from both the solute(s) and solvent (water), i.e.: a) $\Delta \Pi_{s}$, which accounts for the additional volume of the solute and its partial or complete dissociation; b) $\Delta \Pi_{w}$, which accounts for the volume increase due to the associated additional amount of water that causes solute hydration and dissociation, and the associated dilution of the solution.

\subsubsection{Gas-solution analogy}

An important aspect of the osmotic pressure is that it directly relates aqueous and gas phase properties. For instance, for a closed osmotic system at equilibrium and constant $T$ (Fig. 1a), where evaporation and condensation of water molecules above each surface balances, the water vapor pressures above both compartments must equal the corresponding osmotic pressures, i.e. $P_{w}^{(\mathrm{g})}=\Pi_{w}$ and $P_{w, o}^{(\mathrm{g})}=\Pi_{w, o}$, respectively. The total energy of the system is conserved, i.e.

$\Delta E=P_{w}^{(\mathrm{g})} V^{(\mathrm{g})}-P_{w, o}^{(\mathrm{g})} V^{(g)}+\Pi V^{(\mathrm{aq})}-\Pi_{o} V^{(\mathrm{aq})}=0$.

For the gas phase the energy terms (e.g. $\left.P_{w, o}^{(\mathrm{g})} V^{(\mathrm{g})}[\mathrm{kJ}]\right)$ can be expressed with the gas law (with $R[\mathrm{~J} / \mathrm{mol} / \mathrm{K}]$ and $T[\mathrm{~K}]$ ) in terms of moles (e.g. $\left.n_{w, o}^{(\mathrm{g})}[\mathrm{mol}]\right)$, so that e.g. for pure water

$P_{w, o}^{(\mathrm{g})} V^{(\mathrm{g})}=n_{w, o}^{(\mathrm{g})} R T$.

Since equilibrium requires $P_{w, o}^{(\mathrm{g})}=\Pi_{w, o}$, we obtain accordingly for the aqueous phase

$$
\Pi_{w, o} V^{(\mathrm{aq})}=n_{w, o} R T .
$$


Note that this gas-solution analogy also applies to nonreference conditions, whereby Eqs. (2) and (3) remain the same but without the index " $o$ ", and that the gas-solution analogy was noted and used by van 't Hoff and Ostwald about half a decade after Pfeffer's investigations to interpret the osmotic pressure (van 't Hoff, 1887).

The important aspect about this gas-solution analogy is that it already allows to explain the principles of osmosis, whereby it is - together with Arrhenius' theory of partial dissociation of electrolytes in solutions (Arrhenius, 1887) - directly applicable to any solute concentration, provided that the water consumed by hydration is explicitly accounted for.

Therefore, we first generalize in the following the principles that explain osmosis, whereby we consistently account for the amount of water consumed by hydration (Sect. 2.2). Subsequently we transform these equations to atmospheric applications (Sect. 2.3), and reformulate equilibrium thermodynamics to consistently account for water (Sect. 3).

\subsection{Generalizing thermodynamic principles}

To consistently account for the amount of water consumed by hydration, we build on van 't Hoff's gas-solution analogy and Arrhenius' theory of partial dissociation of electrolytes in solutions. We introduce a stoichiometric coefficient for water - analogously to the stoichiometric coefficient(s) for the solute(s) - to explicitly account on a molar basis for the amount of water consumed by hydration.

\subsubsection{Hydration}

The osmotic pressure (Fig. 1a) is caused by the hydration of $n_{s}$ moles of solute. The hydration "consumes" water, which leads to a change in volume. For an equilibrium system any change needs to be compensated, resulting in water uptake. The volume changes because of a) the additional volume of solute, by which the solute partly or completely dissociates due to hydration, b) due to the volume of water that is "consumed" by the hydration, and c) the chemical restructuring of the solute and water molecules. For some hygroscopic solutes, such as e.g. magnesium chloride $\left(\mathrm{MgCl}_{2}\right)$, this restructuring can even lead to a volume depression, whereby the entropy of the hydrated magnesium chloride ions is smaller than that of the crystalline salt (the hydrated $\mathrm{MgCl}_{2}$ ions have a higher structural order occupying less volume).

Strong electrolytes such as $\mathrm{NaCl}$ or $\mathrm{MgCl}_{2}$ dissociate practically completely due to hydration. The chemical dissociation of e.g. sodium chloride $(\mathrm{NaCl})$ (see example given in Fig. 1a) involves water that is consumed by the hydration processes, for which we formulate the equilibrium reaction

$$
\begin{gathered}
1 \times n_{s}^{\mathrm{NaCl}_{(\mathrm{cr})}}+1 \times n_{w}^{\mathrm{H}_{2} \mathrm{O}_{(\mathrm{aq})}} \Leftrightarrow v_{e}^{+} \times n_{s}^{\mathrm{Na}_{(\mathrm{aq})}^{+}}+ \\
v_{e}^{-} \times n_{s}^{\mathrm{Cl}_{(\mathrm{aq})}^{-}}+v_{w}^{+} \times n_{w}^{\mathrm{H}_{3} \mathrm{O}_{(\mathrm{aq})}^{+}}+v_{w}^{-} \times n_{w}^{\mathrm{OH}_{(\mathrm{aq})}^{-}}
\end{gathered}
$$

The subscript " $e$ " denotes the stoichiometric coefficients that account for effective solute dissociation $\left(v_{e}=v_{e}^{+}+v_{e}^{-}\right)$. For strong electrolytes such as $\mathrm{NaCl}$ they equal the stoichiometric coefficients for complete dissociation $\left(v_{s}=v_{s}^{+}+v_{s}^{-}\right)$.

The solute hydration is associated with the consumption of a certain number of water moles. We therefore introduce a stoichiometric coefficient $v_{w}=v_{w}^{+}+v_{w}^{-}$for the solvent (water) to account for the number of moles of solvent (water) needed for solvation (hydration) and solute dissociation. In Fig. 1a the solution (left compartment) contains "waterbinding" particles, and its volume expands at the expense of the right compartment due to water consumption. In case of a closed system the total aqueous $\left(V^{(\mathrm{aq})}\right)$ and gaseous $\left(V^{(\mathrm{g})}\right)$ volumes remain constant. The total change in energy (left and right compartment) can thus be expressed in analogy to Eqs. (2) and (3) in terms of moles of water

$\Delta \Pi_{w} V^{(\mathrm{aq})}=\left(\Pi_{w}-\Pi_{w, o}\right) V^{(\mathrm{aq})}=v_{w} n_{w} R T$.

Similar to Eq. (4a) we can express the energy contained in either of the compartments in terms of the number of moles of solute and solvent, so that for the solution (left compartment)

$\Pi V^{(\mathrm{aq})}=\left(\Pi_{w, o}+\Delta \Pi_{w}\right) V^{(\mathrm{aq})}=\left(v_{w} n_{w}+v_{e} n_{s}\right) R T$.

\subsubsection{Generalized mole fraction}

The ratio of Eqs. (4a) and (4b) provides a very useful expression, as it explicitly relates measurable changes in the osmotic pressure with the actual solute concentration. It may be regarded as the generalized mole fraction $\tilde{\chi}_{w}$

$$
\Delta \Pi_{w} / \Pi=v_{w} n_{w} /\left(v_{w} n_{w}+v_{e} n_{s}\right)=\tilde{\chi}_{w} .
$$

$\tilde{\chi}_{w}$ expresses the ratio of a change relative to the total osmotic pressure of the solution in terms of water needed for the hydration and effective dissociation for any amount of solute (through $v_{w} n_{w}$ and $v_{e} n_{s}$ ).

Note that this generalized mole fraction of water $\left(\tilde{\chi}_{w}\right)$ is introduced to explicitly account for the amount of water consumed by hydration, while the "classical" mole fraction of water is less explicit, being merely defined as $\chi_{w}=n_{w} /\left(n_{w}+n_{s}\right)$. Therefore various correction factors such as the van't Hoff factor, practical osmotic coefficient, or activity coefficients have been introduced in the past to correct the calculated values to the measured ones (Low, 1969).

In analogy to the "classical" solute mole fraction, $\chi_{s}=n_{s} /\left(n_{w}+n_{s}\right)$ we further introduce the generalized mole fraction of the solute, $\tilde{\chi}_{s}=v_{e} n_{s} /\left(v_{w} n_{w}+v_{e} n_{s}\right)$, whereby the sum of the mole fractions is unity $\tilde{\chi}_{s}+\tilde{\chi}_{w}=1$.

Equation (5) involves the following relations:

$$
\begin{aligned}
& -\Delta \Pi=\Delta \Pi_{w}+\Delta \Pi_{s} \Rightarrow \Delta \Pi_{w}=\Delta \Pi-\Delta \Pi_{s}, \\
& \text { - } \Delta \Pi=\Pi-\Pi_{o} \text { with } \Pi=\Pi_{w}+\Pi_{s} \\
& \text { - } \Delta \Pi_{s}=\Pi_{s}-\Pi_{s, o} \text { with } \Pi_{s, o}=0
\end{aligned}
$$




\section{Aerosol water uptake}

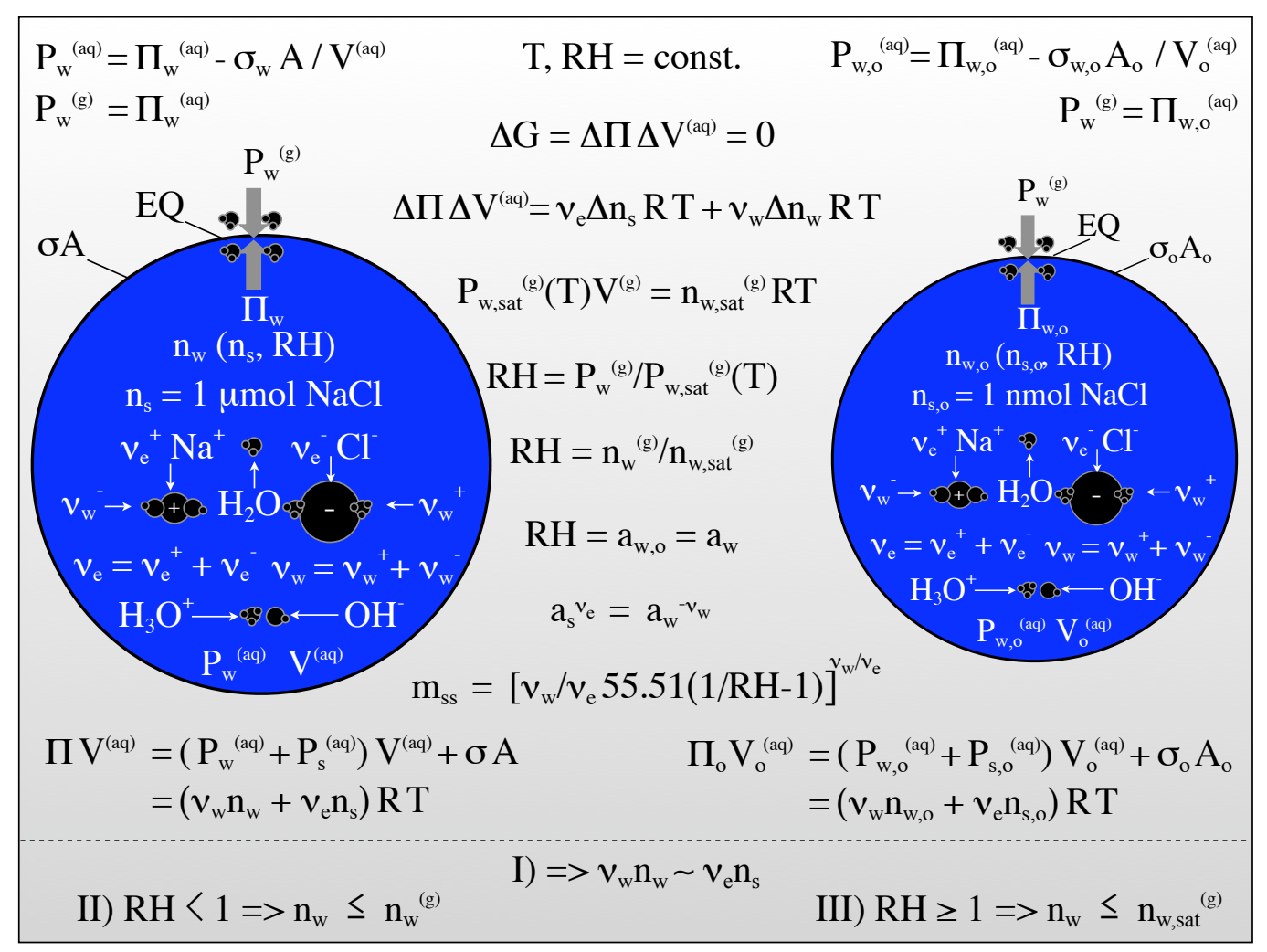

Fig. 1b. Atmospheric conditions: schematic of aerosol water uptake.

- $\Delta \Pi_{w}=\Pi_{w}-\Pi_{w, o}$ with $\Pi_{w, o}=\Pi_{o}$

- $\Delta \Pi_{w} / \Pi=\Pi_{w} / \Pi=-\Pi_{s} / \Pi=1-\tilde{\chi}_{s}$

Equation (5) expresses the fraction of water required for hydration as the system compensates the vapor pressure reduction through a net flow of water from the right into the left compartment (Fig. 1a). For an osmotic (closed) system this results in a change in water activity $\left(\Delta a_{w}=a_{w, o}-a_{w}\right)$, which would equal a (local) change in relative humidity $(\Delta \mathrm{RH})$, since at equilibrium the osmotic pressure of the solute or solvent (in solution) equals the corresponding partial vapor pressure of solute or solvent above the solution.

Note that the osmotic pressure is independent of the curvature of the surface. In contrast to the theoretical solvent partial pressure in solution, the (measurable) osmotic pressure is an effective pressure and hence at equilibrium it implicitly accounts for any surface tension or non-ideality effects. Surface tension (or curvature) affects the solute solubility, and through the solubility the osmotic pressure. We account for surface tension or non-ideality effects by our method through $v_{w}$, as it is a pure function of the solute's solubility and $v_{e}$ (see Sect. 3.4, Eq. 19).

For an open system without a membrane the equilibrium water uptake is the same. It only depends on the hygroscopic nature of the solute, since the water activity is maintained constant by RH. Atmospheric aerosols provide an example of such an open system.

\subsection{Atmosphere}

The principles of osmosis that explain the nature of hygroscopic growth of solutes in the laboratory also apply to atmospheric aerosols. However, in case of equilibrium the situation differs in the atmosphere, since the vapor pressure reduction associated with the hydration of a solute is entirely compensated by water uptake, as schematically shown in Fig. 1b. The reason is that in contrast to controlled equilibrium conditions in the laboratory (closed system at constant $T)$, the aerosol(s) surrounding RH remains - practically constant in the atmosphere (open system), provided that the water vapor concentration does not change due to the relatively small amount of condensing water needed for hydration - a requirement that holds for tropospheric subsaturated conditions $(\mathrm{RH}<1)$ - see also cloud Sect. 4.3.2.

Thus, at constant $T$ and RH the water activity of atmospheric aerosols is fixed at equilibrium by the available water vapor concentration and hence equals the fractional relative humidity $\left(a_{w}=\mathrm{RH}\right)$. Similar to the laboratory a solute 
specific amount of water is required for hydration, whereas in this case the water needs to condense from the gas phase. Furthermore, since $a_{w}=\mathrm{RH}=$ const. for the time period considered to reach equilibrium and no membrane separates solute and solvent, no hydrostatic counter pressure can build up. At equilibrium the vapor pressure reduction is therefore fully compensated by the associated water uptake of the water-binding solute(s)

$\Delta P_{w}^{(\mathrm{g})}=0$.

The equilibrium condition further requires that the total change in energy is zero

$\Delta E=\Delta \Pi \Delta V^{(\mathrm{aq})}=0$.

Changes in energy resulting from the hydration of the solute can be expressed in terms of the effective numbers of moles of hydrated solute(s) and the total amount of water that drives hydration

$\Delta \Pi \Delta V^{(\mathrm{aq})}=v_{e} \Delta n_{s} R T+v_{w} \Delta n_{w} R T$.

Since $\Delta P_{w}^{(\mathrm{g})}=\Delta \Pi=0$, we can rewrite Eq. (8)

$v_{e} \Delta n_{s}=-v_{w} \Delta n_{w}$,

or analogously to Eq. (5), if divided by the osmotic pressure energy of the solution

$v_{e} \Delta n_{s} /\left(v_{w} n_{w}+v_{e} n_{s}\right)=-v_{w} \Delta n_{w} /\left(v_{w} n_{w}+v_{e} n_{s}\right)$,

whereby the total change in the amount of solute $\left(v_{e} \Delta n_{s}\right)$ again causes a change in water activity $\left(\Delta a_{w}\right)$ - equal to a change in relative humidity $(\Delta \mathrm{RH})$ - but compensated by the associated water uptake $\left(-v_{w} \Delta n_{w}\right)$, so that $a_{w}$ and RH remain unchanged. Note that the rhs of Eq. (10) equals Eq. (5) with respect to the reference condition, where $n_{s, o}=n_{w, o}=0$ and $\Delta n_{w}=n_{w}-n_{w, o}$ and $\Delta n_{s}=n_{s}-n_{s, o}$, and that the water activity is defined as the ratio of the fugacity (the real gas equivalent of an ideal gas partial pressure) of the water to its fugacity under reference conditions, usually approximated by the more easily determined ratio of partial pressures.

\section{Reformulating equilibrium thermodynamics}

In this section we reformulate the "classical" equilibrium thermodynamics to consistently include water (see the electronic supplement http://www.atmos-chem-phys.net/7/3163/ 2007/acp-7-3163-2007-supplement.zip for a brief summary of the relevant standard treatment).

One difficulty arising from solution non-idealities is usually circumvented by applying measured activity coefficients - being central in both aerosol thermodynamics and atmospheric modeling - to atmospheric aerosols, but without the required transformation to atmospheric conditions.

The problem is that activity coefficients are usually measured as a function of solute concentration, while in the atmosphere the aerosol activity is not a function of the solute concentration, since the water activity is fixed by $\mathrm{RH}$ if equilibrium is assumed. Although it is well-known that $a_{w}=\mathrm{RH}$ (e.g. Wexler and Potukuchi, 1998), it has been overlooked that this condition fixes all activities, including solute and solvent activity coefficients. Therefore, for a given type of solute they are all a function of $\mathrm{RH}$, independent of their concentration.

Despite, polynomial fits or mathematical approximations are used in atmospheric modeling, which have been derived for various solute activities from laboratory measurements as a function of solute concentrations (e.g. Clegg et al., 1996, 1998; Clegg and Seinfeld, 2006), whereby their application in numerical schemes requires computationally demanding solutions. We will show in the following that we can overcome this, if we (a) explicitly include in all equilibrium reactions the amount of water consumed by solute hydration, and (b) consistently limit the amount of water that is available for condensation, as mentioned in Sect. 2 and described in more detail in Sect. 4.3.2.

According to Sect 2.3, the aerosol water mass is - besides its dependency on $\mathrm{RH}-\mathrm{a}$ function of the mass and type of solute. In contrast, the activity of atmospheric aerosols is only a function of the water vapor mass available for condensation and of the type of solute, but not of its mass.

The amount of water needed for solute hydration is only determined by the solute specific constants $\nu_{e}$ and $v_{w}$ and $\mathrm{RH}$, being independent of the solute concentration (Sect. 2.3). The reason is that only the solutes' solubility determines the amount of solute that can exist in a saturated solution. Any excess of a non-volatile solute can only precipitate out of the solution, so that a solid and aqueous phase co-exist, while (semi)-volatile compounds can additionally evaporate (hence maintaining gas/liquid/solid equilibrium).

This has important implications because for equilibrium conditions the solute specific constants $v_{e}$ and $v_{w}$ enable the explicit calculation of single solute molalities, from which in turn the solute specific water uptake and derived properties can be calculated as a function of RH, $v_{e}$ and $v_{w}$.

Note that this approach extends beyond binary solutions to mixed solutions, under the additional and also quite realistic and widely applied assumption of molar volume additivity (Hänel, 1976), which holds for most soluble salt compounds as they can in principle dissolve completely (depending only on the saturation). Our new approach may also be applied to laboratory conditions if the term $\mathrm{RH}$ used in the following equations is substituted by $a_{w}$.

\subsection{Solubility constants}

Molality is a measure of solubility. At equilibrium the solution is saturated so that it contains the maximum concentration of ions that can exist in equilibrium with its solid (crystalline) phase. The amount of solute that must be added to a given volume of solvent to form a saturated solution is its solubility. At equilibrium the ion product equals the solubil- 
ity product constant $\left(K_{s p}\right)$ for the solute. For instance, using the dissociation equilibrium constant for Reaction (R1) and explicitly accounting for water

$$
\begin{aligned}
\mathrm{K}_{\mathrm{NaCl}_{(\mathrm{cr})}} \times \mathrm{K}_{\mathrm{H}_{2} \mathrm{O}_{(\mathrm{aq})}} & =v_{e}^{+}\left[\mathrm{Na}_{\text {(aq) }}^{+}\right]+v_{e}^{-}\left[\mathrm{Cl}_{(\mathrm{aq})}^{-}\right] \\
& +v_{w}^{+}\left[\mathrm{H}_{3} \mathrm{O}_{(\mathrm{aq})}^{+}\right]+v_{w}^{-}\left[\mathrm{OH}_{(\text {aq) }}^{-}\right],
\end{aligned}
$$

where $\mathrm{K}_{\mathrm{H}_{2} \mathrm{O}_{(\mathrm{aq})}}$ denotes the dissociation equilibrium constant for the associated water mass consumed by hydration, i.e. $\mathrm{K}_{\mathrm{H}_{2} \mathrm{O}(\mathrm{aq})}=v_{w}^{+}\left[\mathrm{H}_{3} \mathrm{O}_{(\mathrm{aq})}^{+}\right]+v_{w}^{-}\left[\mathrm{OH}_{(\mathrm{aq})}^{-}\right]$.

We further express (K1) in terms of activities

$$
\begin{aligned}
\mathrm{K}_{\mathrm{NaCl}_{(\mathrm{cr})}} \times \mathrm{K}_{\mathrm{H}_{2} \mathrm{O}}(\mathrm{aq}) & =a_{s}^{v_{e}} \times a_{w}^{v_{w}} \\
& =a_{\mathrm{Na}^{+}}^{v_{e}^{+}} \times a_{\mathrm{Cl}^{-}}^{v_{e}^{-}} \times a_{\mathrm{H}_{3} \mathrm{O}^{+}}^{v_{w}^{+}} \times a_{\mathrm{OH}^{-}}^{v_{w}^{-}},
\end{aligned}
$$

whereby the subscript " $s$ " denotes the solute activity of the \pm -ion pair, being a product of the cation and anion activity, i.e. for the solute sodium chloride $(\mathrm{NaCl})$ $a_{\mathrm{NaCl}_{(\mathrm{aq})}^{ \pm}}^{v_{e}^{ \pm}}=a_{s}^{v_{e}}=a_{\mathrm{Na}^{+}}^{v_{e}^{+}} \times a_{\mathrm{Cl}^{-}}^{v_{e}^{-}}$. Similarly the subscript “ $w$ " denotes the activity of water, i.e. the water activity $a_{\mathrm{H}_{2} \mathrm{O} \pm_{(\mathrm{aq})}}^{v_{ \pm}^{ \pm}}=a_{w}^{v_{w}}=a_{\mathrm{H}_{3} \mathrm{O}^{+}}^{v^{+}} \times a_{\mathrm{OH}^{-}}^{v_{w}^{-}}$.

Considering that in the atmosphere the water activity is fixed by RH and that the equilibrium condition requires that the total energy change is zero, we can directly derive a relationship between the solute and water activity that allows to considerably simplify the numerical solution of (K2). Since both requirements (a) the equilibrium condition and (b) $a_{w}=\mathrm{RH}$ must also hold for the reference condition with respect to temperature and pressure (i.e. the standard state), the summation over the partial Gibbs free energies $\left(\sum_{i=1}^{k} v_{i j} g_{i j}^{o}\right)$ must be zero if extended to include water

$v_{e} g_{s}^{o}+v_{w} g_{w}^{o}=0$.

The equilibrium condition is fulfilled for a certain relation between the stoichiometric constants, i.e. $v_{w}$ of water causing the hydration of the $v_{e}$ moles of solute, satisfying Eq. (11)

$v_{w}=-v_{e} g_{s}^{o} / g_{w}^{o}$.

This relation between $v_{w}$ and $v_{e}$ requires that the product of activities and subsequently of the equilibrium constants is unity when water is included (see e.g. the electronic supplement http://www.atmos-chem-phys.net/7/3163/ 2007/acp-7-3163-2007-supplement.zip for a definition of equilibrium constants).

Thus, the general formulation for the $j$ th-chemical reaction (e.g. according to K2) yields

$K_{s p, j}=\exp \left(-1 / R T \sum_{i=1}^{k} v_{i j} g_{i j}^{o}\right)=a_{s, j}^{v_{e, j}} \times a_{w, j}^{v_{w, j}}=1$,

being consistent with Eqs. (9) and (10). By dropping the index $j$, i.e.

$a_{s}^{v_{e}}=a_{w}^{-v_{w}}$, or, in terms of equilibrium constants (according to K2), $K_{\mathrm{NaCl}_{(\mathrm{cr})}}=K_{\mathrm{H}_{2} \mathrm{O}_{\text {(aq) }}}^{-1}$.

Thus, at equilibrium the energy gain associated with a neutralization reaction must be compensated for by the energy consumed by the hydration process, so that $d G=0$. This also follows directly from the fact that for charged species, for which the electrical forces must be considered, the potential for an electrochemical reaction is zero at equilibrium in case of electro-neutrality (Nernst, 1889) - a condition that is generally fulfilled for neutralization reactions, which includes the hydration of salt solutes.

\subsection{Aerosol activities}

In general, an aerosol system is not in equilibrium if the ion product deviates from the solubility product constant of the solute. But it can rapidly adjust according to Le Chatelier's principle, by which the reaction re-equilibrates after excess ions precipitate or dissolve until the ion product deficit is compensated. The solubility product constant for a saturated binary solution (one solute and solvent) requires that $v_{e}^{+}$cations are released for $v_{e}^{-}$anions, so that at equilibrium

$a_{s+}^{v_{e}^{+}}=a_{s-}^{v_{e}^{-}}=a_{w+}^{-v_{w}^{+}}=a_{w-}^{-v_{w}^{-}}$.

$a_{s+}^{v_{e}^{+}}$and $a_{s-}^{v_{e}^{-}}$denote the solute's $(s)$ cation (+) and anion (-) activity; $a_{w+}^{-v_{w}^{+}}$and $a_{w-}^{-v_{w}^{-}}$denote the water activities. On a molal scale (moles of solute per kilogram solvent), the solute activity is defined in terms of molality and corrected by the molal activity coefficient

$$
\begin{aligned}
a_{s}^{v_{e}}=a_{s+}^{v_{e}^{+}} \times a_{s-}^{v_{e}^{-}} & =\left(\gamma_{s+} \times m_{s+}\right)^{v_{e}^{+}} \times\left(\gamma_{s-} \times m_{s-}\right)^{v_{e}^{-}} \\
& =\gamma_{s \pm}^{v_{e}} \times m_{s+}^{v_{e}^{+}} \times m_{s-}^{v_{e}^{-}}=\left(\gamma_{s \pm} \times m_{s \pm}\right)^{v_{e}} .
\end{aligned}
$$

$m_{s+}^{v_{e}^{+}}, m_{s-}^{v_{e}^{-}}$and $m_{s \pm}$ denote the cation, anion and the ionpair molality; $\gamma_{s+}^{v_{e}^{+}}, \gamma_{s-}^{v_{e}^{-}}$and $\gamma_{s \pm}=\left(\gamma_{s+}^{v_{e}^{+}} \times \gamma_{s-}^{v_{e}^{-}}\right)^{1 / v_{e}}$ are the molal activity coefficients of the cation, anion and the mean ion-pair activity coefficient of the solute, respectively; $v_{e}^{+}$ and $v_{e}^{-}$are their stoichiometric constants, i.e. the effective number of moles of cations and anions per mole dissociating solute $(s)$. The aqueous single solute $(s s)$ molality is defined as $m_{s s}=55.51 \times n_{s} / n_{w}$, with $n_{s}$ and $n_{w}$, the number of moles [mol] of solute and solvent (water). 55.51=1000/ $M_{w}$ $\left[\mathrm{mol} / \mathrm{kg} \mathrm{H} \mathrm{H}_{2} \mathrm{O}\right]$ is the molal concentration of water, with $M_{w}=18.015[\mathrm{~g} / \mathrm{mol}]$ the molar mass of water.

\subsection{Solubility}

For a saturated binary solution, $n_{s}$ and $n_{w}$ can be directly determined from the solute solubility. The solubility can be expressed in terms of the saturation molality of the single solute, or as mass of solute per 100 gram of water, or mass 
Table 1a. Thermodynamic data.

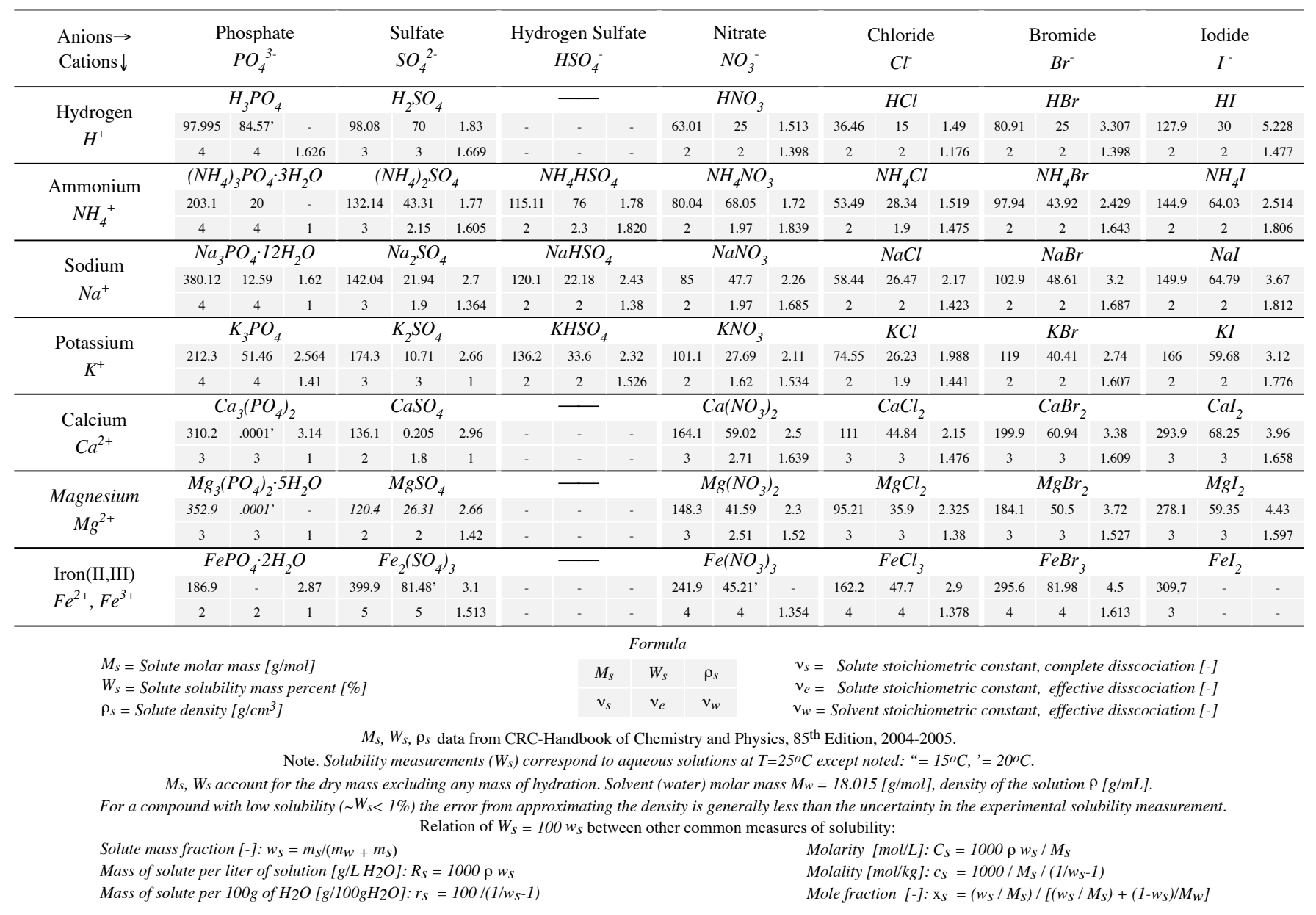

percent $W_{s}$ [\%], i.e. mass of solute per total mass of solution (solute and solvent). For the latter

$$
W_{s}=100 \times w_{s}=100 \times m_{s} /\left(m_{s}+m_{w}\right),
$$

where $w_{s}$ denotes the solute mass fraction, $m_{s}=n_{s} M_{s}$ and $m_{w}=n_{w} M_{w}$ the mass $[g]$ of solute and solvent (water), respectively; $M_{s}$ and $M_{w}$ are the corresponding molar masses of solute and solvent $[\mathrm{g} / \mathrm{mol}]$.

At equilibrium a solution is saturated, i.e. it contains the maximum number of moles of solute that can be dissolved. If the solubility is known, this number can be directly calculated from the total mass of solution (fixed to $1000 \mathrm{~g}$ ) from

$n_{s}=1000 / M_{s} \times w_{s}$.

The associated number of (free) moles of water of the solution can be obtained from

$n_{w}=1000 / M_{w} \times\left(1-w_{s}\right)$.
The saturation molality is then related to the solute mass fraction (solubility) by

$m_{s s, s a t}=1000 / M_{s} \times 1 /\left(1 / w_{s}-1\right)$,

and the mass of hydrated solute can be expressed in terms of water by

$\tilde{n}_{w} M_{w}=1000 \times w_{s}$.

The relation between the moles of water is given by $\tilde{n}_{w}=n_{w, o}-n_{w}$, with $n_{w, o}=55.51[\mathrm{~mol}]$.

\subsection{Stoichiometric constant of water}

The stoichiometric constant of water $\left(v_{w}\right)$ that hydrates one mole of solute into $v_{e}$ moles is related to $v_{e}$ according to Eq. (9) by $v_{e} \Delta n_{s}=-v_{w} \Delta n_{w}$. The term on the rhs expresses the amount of water required for the hydration of $\Delta n_{s}$ moles of solute (where $\Delta n_{w}<0$ since water is consumed), in equilibrium giving rise to an effective dissociation into $v_{e}$ moles. 
Table 1b. Continued.

\begin{tabular}{|c|c|c|c|c|c|c|c|c|c|c|c|c|c|c|c|c|c|c|c|c|c|}
\hline $\begin{array}{l}\text { Anions } \rightarrow \\
\text { Cations } \downarrow\end{array}$ & \multicolumn{3}{|c|}{$\begin{array}{l}\text { Carbonate } \\
\mathrm{CO}_{3}{ }^{2-}\end{array}$} & \multicolumn{3}{|c|}{$\begin{array}{l}\text { Hydrogen Carbonate } \\
\qquad \mathrm{HCO}_{3}^{-}\end{array}$} & \multicolumn{3}{|c|}{$\begin{array}{c}\text { Hydroxide } \\
\mathrm{OH}^{-}\end{array}$} & \multicolumn{3}{|c|}{$\begin{array}{l}\text { Formate } \\
\mathrm{CHO}_{2}^{-}\end{array}$} & \multicolumn{3}{|c|}{$\begin{array}{l}\text { Acetate } \\
\mathrm{C}_{2} \mathrm{H}_{3} \mathrm{O}_{2}^{-}\end{array}$} & \multicolumn{3}{|c|}{$\begin{array}{l}\text { Oxalate } \\
\mathrm{C}_{2} \mathrm{O}_{4}^{2-}\end{array}$} & \multicolumn{3}{|c|}{$\begin{array}{c}\text { Citrate } \\
\mathrm{C}_{6} \mathrm{H}_{5} \mathrm{O}_{7}{ }^{3-}\end{array}$} \\
\hline \multirow{3}{*}{$\begin{array}{c}\text { Hydrogen } \\
H^{+}\end{array}$} & \multicolumn{3}{|c|}{$\mathrm{H}_{2} \mathrm{CO}_{3}$} & \multicolumn{3}{|c|}{-} & \multicolumn{3}{|c|}{$\mathrm{H}_{2} \mathrm{O}$} & \multicolumn{3}{|c|}{$\mathrm{CH}_{2} \mathrm{O}_{2}$} & \multicolumn{3}{|c|}{$\mathrm{C}_{2} \mathrm{H}_{4} \mathrm{O}_{2}$} & \multicolumn{3}{|c|}{$\mathrm{C}_{2} \mathrm{H}_{2} \mathrm{O}_{4}$} & \multicolumn{3}{|c|}{$\mathrm{C}_{6} \mathrm{H}_{8} \mathrm{O}_{7}$} \\
\hline & 62.025 & - & - & - & - & - & 18.015 & 100 & 0.997 & 46.03 & 68 & 1.22 & 60.05 & 23 & 1.045 & 90.04 & $8.69^{\prime}$ & 1.9 & 192.1 & $59^{\prime}$ & 1.665 \\
\hline & 3 & - & - & - & - & - & 2 & 2 & - & 2 & 2 & 1.833 & 2 & 2 & 1.362 & 3 & 3 & 1.000 & 4 & 4 & 1.470 \\
\hline \multirow{3}{*}{$\begin{array}{c}\text { Ammonium } \\
\mathrm{NH}_{4}^{+}\end{array}$} & \multicolumn{3}{|c|}{$\left(\mathrm{NH}_{4}\right)_{2} \mathrm{CO}_{3}$} & \multicolumn{3}{|c|}{$\mathrm{NH}_{4} \mathrm{HCO}_{3}$} & \multicolumn{3}{|c|}{$\mathrm{NH}_{4} \mathrm{OH}$} & \multicolumn{3}{|c|}{$\mathrm{NH}_{4} \mathrm{CHO}_{2}$} & \multicolumn{3}{|c|}{$\mathrm{NH}_{4} \mathrm{C}_{2} \mathrm{H}_{3} \mathrm{O}_{2}$} & \multicolumn{3}{|c|}{$\left(\mathrm{NH}_{4}\right)_{2} \mathrm{C}_{2} \mathrm{O}_{4}$} & \multicolumn{3}{|c|}{$\left(\mathrm{NH}_{4}\right)_{2} \mathrm{HC}_{6} \mathrm{H}_{5} \mathrm{O}_{7}$} \\
\hline & 96.086 & $50.00^{\prime \prime}$ & - & 79.06 & 19.87 & 1.586 & 35.05 & 100 & - & 63.06 & 58.85 & 1.27 & 77.08 & 59.68 & 1.073 & 124.1 & 4.94 & 1.5 & 226.2 & - & 1.48 \\
\hline & 3 & 3 & 1.523 & 2 & 2 & 1.298 & 2 & 2 & 2 & 2 & 2 & 1.77 & 2 & 2 & 1.776 & 3 & 3 & 1 & 4 & - & - \\
\hline \multirow{3}{*}{$\begin{array}{l}\text { Sodium } \\
\mathrm{Na}^{+}\end{array}$} & \multicolumn{3}{|c|}{$\mathrm{Na}_{2} \mathrm{CO}_{3}$} & & $\overline{a H C C}$ & & & $\mathrm{NaOH}$ & & & $\mathrm{VaCHC}$ & & & $\mathrm{C}_{2} \mathrm{H}$ & & & $a_{2} C_{2}$ & & & & \\
\hline & 105.99 & 23.49 & 2.54 & 84.01 & 9.34 & 2.2 & 40.0 & 50 & 2.13 & 68.01 & 48.69 & 1.92 & 82.03 & 33.51 & 1.528 & 134 & 3.48 & 3.61 & 258.1 & - & - \\
\hline & 3 & 1.9 & 1.393 & 2 & 2 & 1 & 2 & 2 & 1.7 & 2 & 2 & 1.687 & 2 & 2 & 1.525 & 3 & 3 & 1 & 4 & - & - \\
\hline & & $\mathrm{K}_{2} \mathrm{CO}_{3}$ & & & $\mathrm{KHCO}$ & & & $\mathrm{KOH}$ & & & $\mathrm{KCHO}$ & & & $\overline{C_{2} H_{3}}$ & & $\mathrm{~K}_{2} \mathrm{C}$ & ${ }_{2} \mathrm{O}_{4} \cdot \mathrm{I}$ & ${ }_{2} \mathrm{O}$ & & ${ }_{6} H$ & \\
\hline Potassium & 138.21 & 52.61 & 22.9 & 100.1 & 25.78 & 2.17 & 56.11 & 54.75 & 2.044 & 84.12 & $76.80^{\prime}$ & 1.91 & 98.14 & 72.9 & 1.57 & 184.2 & 26.68 & 2.13 & 306.4 & - & - \\
\hline & 3 & 3 & 1.545 & 2 & 2 & 1.411 & 2 & 2 & 1.738 & 2 & 2 & 1.885 & 2 & 2 & 1.863 & 3 & 3 & 1.25 & 4 & - & - \\
\hline Calcium & & $\mathrm{CaCO}_{3}$ & & & $\overline{-}$ & & & $a(\mathrm{OH}$ & & & $\mathrm{a}(\mathrm{CHO}$ & & & $\overline{C_{2} H_{3}}$ & & & $\overline{\mathrm{FaC}_{2} \mathrm{C}}$ & & $\mathrm{Ca}$ & $\overline{\Gamma H}$ & $\left.\mathrm{O}_{7}\right)_{2}$ \\
\hline Calcium & 100.09 & 0.0007 & 2.83 & - & - & - & 74.09 & $0.16^{\prime}$ & 2.2 & 130.1 & $14.24^{\prime}$ & 2.02 & 158.2 & - & 1.5 & 128.1 & .0006 & 2.2 & 498.4 & - & - \\
\hline & 2 & 2 & 1 & - & - & - & 3 & 3 & 1 & 3 & 3 & 1 & 3 & - & - & 2 & 2 & 1 & 5 & - & - \\
\hline Magnesium & & $\mathrm{AgCO}$ & & & 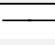 & & & $\lg (\mathrm{OH}$ & & $M g(C$ & $\left.\mathrm{HO}_{2}\right)_{2}$ & $\mathrm{H}_{2} \mathrm{O}$ & $M g$ & $\mathrm{C}_{2} \mathrm{H}_{3}$ & & & $\overline{\mathrm{IgC} C_{2} \mathrm{C}}$ & & $M g$ & 6 & $\left.\mathrm{O}_{7}\right)_{2}$ \\
\hline Magnesium & 84.314 & $0.018^{\prime}$ & 3.05 & - & - & - & 58.32 & .0007 , & 2.37 & 150.4 & - & - & 142.4 & 39.61 & 1.5 & 112.3 & - & - & 451 & - & - \\
\hline & 2 & 2 & 1 & - & - & - & 3 & 3 & 1 & 3 & - & - & 3 & 3 & 1.421 & 2 & - & - & 5 & - & - \\
\hline & & $\mathrm{FeCO}_{3}$ & & & 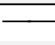 & & & $e(\mathrm{OH}$ & & & $e(\mathrm{CHO}$ & & $\mathrm{FeO}$ & $\overline{I\left(C_{2} I\right.}$ & $\left.\mathrm{O}_{2}\right)_{2}$ & & ${ }_{2}\left(C_{2} C\right.$ & & $\mathrm{FeC}_{6}$ & 5 & $\mathrm{H}_{2} \mathrm{O}$ \\
\hline Iron $(11,111)$ & 115.85 & .00006 & 3.9 & - & - & - & 106.9 & - & 3.12 & 190.9 & 45.21 & - & 190.9 & - & - & 375.8 & - & - & 335 & - & - \\
\hline$F e^{-1}, F e^{-1}$ & 2 & 2 & 1 & - & - & - & 4 & - & - & 4 & 4 & 1.354 & 4 & - & - & 5 & - & - & 2 & - & - \\
\hline & & mmon & & & Icetor & & & Iethan & & & Ethano & & & Fruct & & & Mann & & & cro & \\
\hline & & $\mathrm{NH}_{3}$ & & & $\left.\mathrm{H}_{3}\right)_{2}$ & & & $\mathrm{CH}_{3} \mathrm{O}$ & & & $\mathrm{H}_{3} \mathrm{CH}_{2}$ & & & ${ }_{6} \mathrm{H}_{12}$ & & & ${ }_{6} H_{14}$ & & & & \\
\hline & 17.031 & 30 & 0.696 & 58.08 & 10 & 0.785 & 32.04 & 100 & 0.791 & 46.07 & 100 & 0.789 & 180.2 & 48 & 1.6 & 182.2 & 15 & 1.489 & 342.3 & 80 & 1.581 \\
\hline & 1 & 1 & 1.778 & 3 & 3 & 1 & 2 & 2 & 2 & 3 & 3 & 1.824 & 6 & 6 & 1.204 & 11 & 11 & 1 & 11 & 11 & 1.163 \\
\hline
\end{tabular}

Recalling that at equilibrium a binary solution is saturated, for which the solubility product constant requires that $v_{e}^{+}$cations are released for $v_{e}^{-}$anions with the total of $v_{e}=v_{e}^{+}+v_{e}^{-}$ions of solute, and for which electroneutrality requires that $v_{w}^{+}$moles of $\mathrm{H}_{3} \mathrm{O}_{(\mathrm{aq})}^{+}$and $v_{w}^{-}$moles of $\mathrm{OH}_{(\mathrm{aq})}^{-}$ must be involved in the hydration of each mole of solute, whereby two moles of water are consumed for each mole of $\mathrm{H}_{3} \mathrm{O}_{(\text {aq })}^{+}$and $\mathrm{OH}_{(\text {aq })}^{-}$produced, we can express the stoichiometric constant of water as

$v_{w}=v_{w, o}+\log \left(2 / v_{e} \times 1000 w_{s}\right)$,

with $1000 w_{s}=\tilde{n}_{w} M_{w}$ according to Eq. (18d).

Table 1 lists the stoichiometric constants of water together with the required thermodynamic data for nearly $100 \mathrm{com}-$ pounds.

Note that $v_{w}$ is determined by the solubility. For near$100 \%$ solubility $v_{w}$ converges to 2 (theoretically to 2.301 ), while for less soluble compounds $\left(W_{s} \leq 10 \%\right) v_{w}$ approaches unity. For pure water $v_{w}$ is not defined and not needed. $v_{w, o}=-1$ and indicates that each mole of hydrated solute "consumes" $\log \left(2 / v_{e} \times 1000 w_{s}\right)$ moles of water.

\subsection{Single solute molality}

The water mass consumed by solute hydration is for a closed system (Fig. 1a) the same as for an open system
(Fig. 1b). According to Eq. (9) the water uptake is proportional to the amount of solute, whereby the relative amount of water is given by the mole fraction of water, or by the molality $m_{s s}=55.51 n_{s} / n_{w}\left[\mathrm{~mol} / \mathrm{kg} \mathrm{H}_{2} \mathrm{O}\right]$. The molality and the mole fraction of water are related by $x_{w}=n_{w} /\left(n_{w}+n_{s}\right)=1 /\left(1+n_{s} / n_{w}\right)=1 /\left(1+m_{s s} / 55.51\right)$.

According to Eq. (5) the osmotic pressure change for water $\Delta \Pi_{w}$ equals the osmotic pressure of water $\Pi_{w}$, so that at equilibrium the ratio of $\Pi_{w}$ to the total osmotic pressure of the solution equals the relative humidity, i.e. $\Pi_{w} / \Pi=\mathrm{RH}$. Since $\Pi_{w} / \Pi=\tilde{\chi}_{w}=1 /\left(1+v_{e} n_{s} / v_{w} n_{w}\right)$, we can directly derive $m_{s s}$ from RH if $v_{e}$ and $v_{w}$ are known

$m_{s s}=\left[v_{w} / v_{e} 55.51(1 / \mathrm{RH}-1)\right]^{v_{w} / v_{e}}$.

Note the transformation of $n_{s} / n_{w}$ into molality (multiplication of both sides with $1000 / M_{w}=55.51$, and considering that $m_{s s} \rightarrow m_{s s}^{v_{e} / v_{w}}$ ).

Figure 2a shows single solute molalities as a function of RH for four selected compounds from Table 1. Note that the full set of figures is presented in the electronic supplement (http://www.atmos-chem-phys.net/7/3163/2007/ acp-7-3163-2007-supplement.zip), and that RH equals the water activity $\left(a_{w}\right)$. The single solute molalities include:

1. Measurements used in various thermodynamic equilibrium models (EQMs) (black line) . Water activity data of $\mathrm{NaNO}_{3}, \mathrm{Na}_{2} \mathrm{SO}_{4}, \mathrm{NaHSO}_{4},\left(\mathrm{NH}_{4}\right)_{2} \mathrm{SO}_{4}$, 

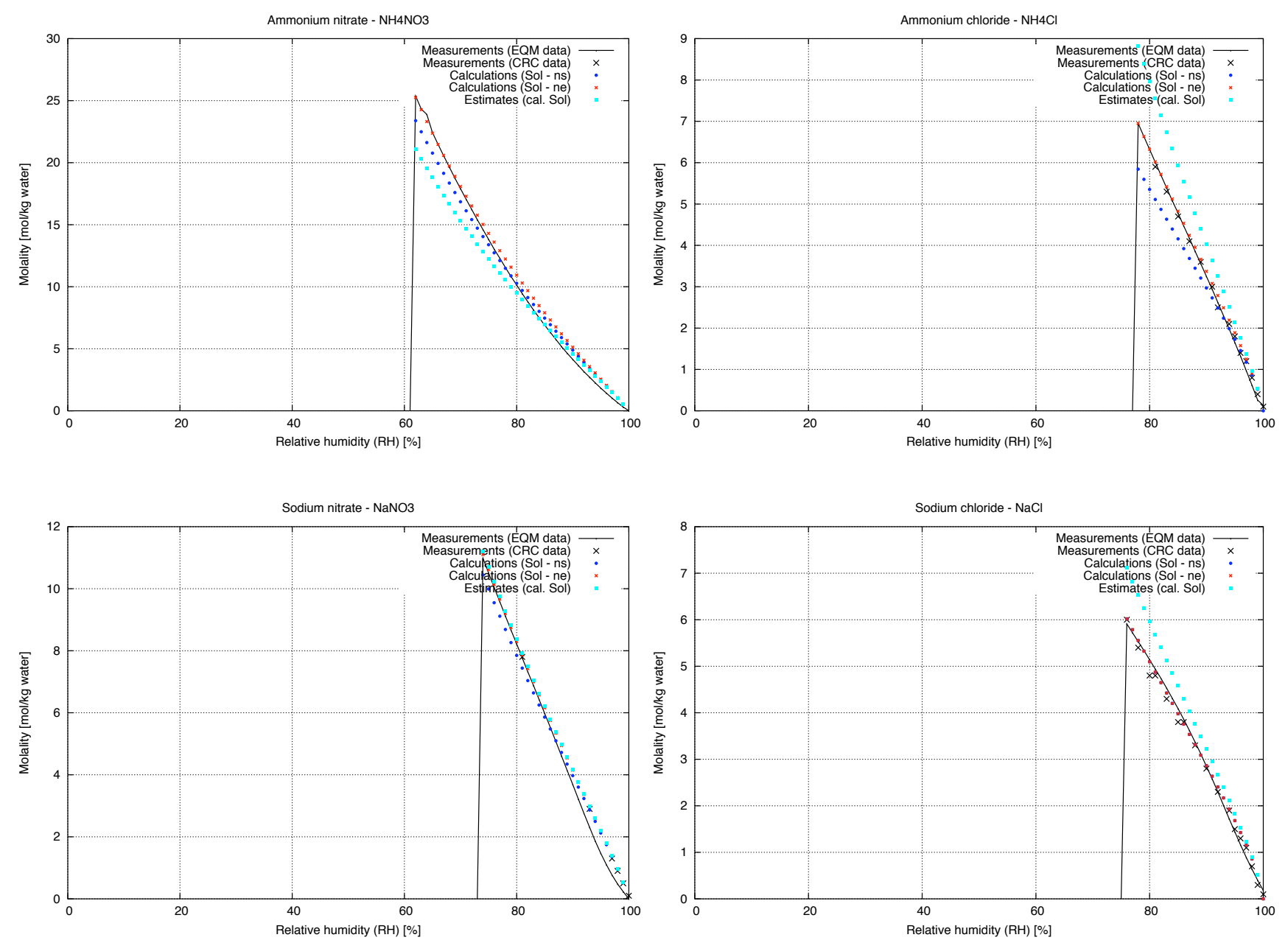

Fig. 2a. (a) Single solute molalities, (b) associated water mass (aerosol water uptake). Shown is a selection of figures presented in the electronic supplement (http://www.atmos-chem-phys.net/7/3163/2007/acp-7-3163-2007-supplement.zip, Fig. A1).

$\left(\mathrm{NH}_{4}\right) \mathrm{HSO}_{4}$ from Tang and Munkelwitz (1994), $\mathrm{NH}_{4} \mathrm{NO}_{3}$ from Chan et al. (1992), $\mathrm{KCl}$ from Cohen et al. (1987). All other sources are given in Kim et al. (1993a, 1994b).

2. Measurements as listed in the CRC Handbook of Chemistry and Physics (2006) (black crosses).

3. Calculations according to Eq. (20) using CRC-solubility measurements to derive $v_{w}$ by assuming complete dissociation $\left(v_{s}\right)$ (blue dots).

4. Same as (3) but considering effective dissociation $\left(v_{e}\right)$ (red crosses).

5. Estimates based on calculated solubility assuming that the solubility approximates one minus the ratio of initial molar volumes of water $\left(V_{w}\right)$ and solute $\left(V_{s}\right)$, i.e. $w_{s}=1-V_{w} / V_{s}$, with $V_{w}=M_{w} / \rho_{w}$ and $V_{s}=M_{s} / \rho_{s}$, where $\rho_{w}$ and $\rho_{s}$ denote the density $\left[\mathrm{g} / \mathrm{cm}^{3}\right]$ of water and solute, respectively (turquoise squares).
Figure 2a shows that Eq. (20) based on $v_{e}$ is in excellent agreement with the measurement data used in various EQMs, e.g. ISORROPIA (Nenes et al., 1998) and SCAPE (Kim et al., 1993a, b, 1995), SCAPE2 (Meng et al., 1995), as previously used by Metzger et al. (2006), and with inferred measurements from the CRC Handbook. The single solute molalities plotted against RH start from saturation water activity, i.e. the relative humidity of deliquescence (RHD) up to water vapor saturation $(\mathrm{RH}=1)$. Note that usually the single solute molalities are plotted against water activity which in this case equals RH. For all cases where water activity data from SCAPE2 were available also RHD values were derived. For all other cases, the single solute molalities are plotted over the entire RH range and only for some compounds a comparison with the inferred CRC measurements is possible. All other data should be regarded as predictions, for which we assumed complete dissociation $\left(v_{s}\right)$ so that the two lines (blue dots and red crosses) are identical. 
Table 2. Relative humidity of deliquescence (RHD) as used in various EQMs (see text for details). All values correspond to $T=298 \mathrm{~K}$.

\begin{tabular}{|c|c|c|c|c|c|c|c|c|c|c|c|c|c|c|}
\hline & $\mathrm{PO}_{4}{ }^{3-}$ & $\mathrm{SO}_{4}{ }^{2-}$ & $\mathrm{HSO}_{4}^{-}$ & $\mathrm{NO}_{3}^{-}$ & $\mathrm{Cl}^{-}$ & $\mathrm{Br}^{-}$ & $\mathrm{I}^{-}$ & $\mathrm{CO}_{3}^{2-}$ & $\mathrm{HCO}_{3}^{-}$ & $\mathrm{OH}^{-}$ & $\mathrm{CHO}_{2}^{-}$ & $\mathrm{C}_{2} \mathrm{H}_{3} \mathrm{O}_{2}^{-}$ & $\mathrm{C}_{2} \mathrm{O}_{4}^{2-}$ & $\mathrm{C}_{6} \mathrm{H}_{5} \mathrm{O}_{7}{ }^{3-}$ \\
\hline $\mathrm{H}^{+}$ & -- & -- & -- & -- & -- & -- & -- & -- & -- & -- & -- & -- & -- & -- \\
\hline $\mathrm{NH}_{4}^{+}$ & -- & 0.7997 & 0.4000 & 0.6183 & 0.7710 & -- & -- & -- & -- & -- & -- & -- & -- & -- \\
\hline $\mathrm{Na}^{+}$ & -- & 0.9300 & 0.5200 & 0.7379 & 0.7528 & -- & -- & 0.8977 & 0.9640 & -- & -- & -- & -- & -- \\
\hline $\mathrm{K}^{+}$ & -- & 0.9751 & -- & 0.9300 & 0.8426 & -- & -- & -- & -- & -- & -- & -- & -- & -- \\
\hline $\mathrm{Ca}^{2+}$ & -- & 0.9700 & -- & 0.4906 & 0.2830 & -- & -- & -- & -- & -- & -- & -- & -- & -- \\
\hline $\mathrm{Mg}^{2+}$ & -- & 0.8613 & -- & -- & 0.3284 & -- & -- & -- & -- & -- & -- & -- & -- & -- \\
\hline $\mathrm{Fe}^{3+}$ & -- & - & -- & -- & -- & -- & -- & -- & -- & -- & -- & -- & -- & -- \\
\hline & -- & -- & -- & -- & -- & -- & -- & -- & -- & -- & -- & -- & -- & -- \\
\hline
\end{tabular}

Table 3. Calculated RHD based on $v_{w}$ from measured solubility and effective dissociation $\left(v_{e}\right)$ according to Eq. (21). Note that values are given when solubility measurements were available (listed in Table 1) and that these values strongly depend on the solubility.

\begin{tabular}{|c|c|c|c|c|c|c|c|c|c|c|c|c|c|c|}
\hline & $\mathrm{PO}_{4}{ }^{3-}$ & $\mathrm{SO}_{4}^{2-}$ & $\mathrm{HSO}_{4}^{-}$ & $\mathrm{NO}_{3}^{-}$ & $\mathrm{Cl}^{-}$ & $\mathrm{Br}^{-}$ & $\mathrm{I}^{-}$ & $\mathrm{CO}_{3}^{2-}$ & $\mathrm{HCO}_{3}^{-}$ & $\mathrm{OH}^{-}$ & $\mathrm{CHO}_{2}^{-}$ & $\mathrm{C}_{2} \mathrm{H}_{3} \mathrm{O}_{2}^{-}$ & $\mathrm{C}_{2} \mathrm{O}_{4}^{2-}$ & $\mathrm{C}_{6} \mathrm{H}_{5} \mathrm{O}_{7}{ }^{3-}$ \\
\hline $\mathrm{H}^{+}$ & 0.0011 & 0.0939 & -- & 0.7816 & 0.6908 & 0.8366 & 0.8886 & -- & -- & 0.0000 & 0.4370 & 0.7818 & 0.9400 & 0.0784 \\
\hline $\mathrm{NH}_{4}^{+}$ & 0.8581 & 0.7980 & 0.3999 & 0.6067 & 0.7659 & 0.7839 & 0.7572 & 0.2182 & 0.8610 & 0.0019 & 0.5907 & 0.6387 & 0.9960 & -- \\
\hline $\mathrm{Na}^{+}$ & 0.9985 & 0.9390 & 0.9285 & 0.7476 & 0.7540 & 0.7713 & 0.7593 & 0.9051 & 0.9486 & 0.5160 & 0.6732 & 0.7965 & 0.9989 & 0.5927 \\
\hline $\mathrm{K}^{+}$ & 0.1699 & 0.9827 & 0.8836 & 0.9279 & 0.8429 & 0.8363 & 0.8075 & 0.3334 & 0.8704 & 0.5850 & 0.5154 & 0.5964 & 0.8187 & -- \\
\hline $\mathrm{Ca}^{2+}$ & -- & 1.0000 & -- & 0.4806 & 0.3228 & 0.3922 & 0.4559 & -- & -- & -- & 0.8990 & -- & -- & -- \\
\hline $\mathrm{Mg}^{2+}$ & -- & 0.8950 & -- & 0.7161 & 0.3508 & 0.4945 & 0.5676 & -- & -- & -- & -- & 0.5117 & -- & -- \\
\hline \multirow[t]{2}{*}{$\mathrm{Fe}^{3+}$} & -- & 0.0060 & -- & 0.3338 & 0.1126 & 0.0248 & 0.9992 & -- & -- & -- & 0.1994 & -- & -- & -- \\
\hline & 0.9415 & 0.7255 & 0.0018 & 0.0000 & 0.0032 & 0.8776 & 0.0000 & -- & -- & -- & -- & -- & -- & -- \\
\hline
\end{tabular}

Only in case of EQM water activity measurements we could determine the effective dissociation $\left(v_{e}\right)$ by using an optimal fit of Eq. (20) to the measurements where necessary, as for instance for $\mathrm{NH}_{4} \mathrm{Cl}$. The accuracy of the results of Eq. (20) is then dependent on the accuracy of these measurements. However, strong electrolytes practically completely dissociate; $\mathrm{NaNO}_{3}$ and $\mathrm{NaCl}$ have almost identical $v_{s}$ and $v_{e}$, which provides some confidence in both the measurements and Eq. (20). For cases where $v_{s}$ and $v_{e}$ differ we can see the sensitivity of Eq. (20) to these parameters. Similarly, the single solute molality estimates based on simple solubility approximations (turquoise squares) additionally indicate the sensitivity of $m_{s s}(\mathrm{RH})$ to uncertainties in the solubility data. It is important to note that only concentration independent constants have been used over the entire concentration range to predict the single solute molalities of various solutes for all cases. 1

\footnotetext{
${ }^{1}$ The single solute molality measurements in the CRC Handbook are listed as a function of solubility $\left(W_{s}=100 \times w_{s}\right)$ rather than water activity $\left(a_{w}\right)$. We therefore plotted the molality (black crosses) against the water activity only when the solubility values matched those derived from Eq. (20). Although this can lead to a bias in the comparison, in particular for the steepness of the $m_{s s}(\mathrm{RH})$ functions, we can evaluate the accuracy of this comparison for all cases where we additionally have measurements available, as used in EQMs. Since the agreement is rather good, and since the CRC solubility measurements and those derived from Eq. (20) must match at the saturation water activity (i.e. at the RHD), which fixes the steepness of the $m_{s s}(\mathrm{RH})$ function, we have included the CRC measurements also for cases where we do not have independent measurements. Especially the steepness of the $m_{s s}(\mathrm{RH})$ functions of the 7 non-electrolytes (Table 1; for fig-
}

\subsection{Relative humidity of deliquescence (RHD)}

The relative humidity of deliquescence (RHD) describes the relative humidity at which a solid salt deliquesces through water uptake. At equilibrium a solution is saturated and the corresponding RH equals the RHD of the salt. The RHD can therefore be directly computed with Eq. (20). Rearranging Eq. (20) and solving for RH, i.e. with RH=RHD

$\mathrm{RHD}=\left(v_{e} / v_{w} m_{s s, \mathrm{sat}}^{v_{e} / v_{w}} / 55.51+1\right)^{-1}$,

whereby we obtain the saturation molality $\left(m_{s s, \text { sat }}\right)$ from the solute's solubility according to Eq. (18c).

Table 2 lists RHD values used by various EQMs (see e.g. Metzger, 2000, for details) and previously applied by Metzger et al. (2002, 2006), while Table 3 lists all (predicted) RHD values obtained with Eq. (21) for all compounds listed

ures see electronic supplement http://www.atmos-chem-phys.net/7/ 3163/2007/acp-7-3163-2007-supplement.zip) strongly depend on the assumptions for $v_{e}$ and $v_{s}$. By assuming a value of one for either $v_{e}$ or $v_{s}$, the steepness of all $m_{s s}(\mathrm{RH})$ functions of the 7 non-electrolytes increase as strongly as the one of ammonia $\left(\mathrm{NH}_{3}\right)$, which seems unrealistic for the alcohols and sugars as it would indicate a very low solubility. Furthermore, the agreement with CRC measurements is then quite poor, as only the very first water activity measurements near unity match (not shown). Only for the $v_{e}$ and $v_{S}$ values given in Table 1 , the relatively best agreement with the CRC measurements is achieved in terms of a maximum number of solubility data points that matches. This indicates, however, that - probably as a rule of thumb - approximately each fractional group or oxygen atom becomes hydrated, so that e.g. $v_{e}=11$ for Dmannitol and sucrose. 
in Table 1 . Note that Table 2 only contains RHD values for those compounds of Table 1 that are included in the cited EQMs. Note further that Eq. (21) further allows to calculate efflorescence and deliquescence RHDs of single or mixed salt solutions (see Sect. 4.1 point 5 and 9), whereby these values provide additional support for the accuracy of Eq. (20).

\subsection{Aerosol associated water mass}

The water mass associated with atmospheric aerosols can be obtained for single solute or mixed solutions from the definition of molality $\left(m_{s s}=55.51 n_{s} / n_{w}\right)$ using Eq. (20)

$$
\begin{aligned}
m_{w, s s} & =n_{s} / m_{s s} \\
& =n_{s} \times\left[v_{w} / v_{e} 55.51(1 / \mathrm{RH}-1)\right]^{-v_{w} / v_{e}} .
\end{aligned}
$$

The total water mass associated with a mixed solution containing $n$-single solutes is in case of osmotic pressure additivity the sum of the water masses associated with all single solute solutions

$m_{w}=\sum_{j=1}^{n} n_{s, j} / m_{s s, j}$.

Figure $2 \mathrm{~b}$ shows (according to Fig. 2a) the aerosol water mass as a function of $\mathrm{RH}$ for four selected compounds, calculated with Eq. (22) for single solute solutions containing $1 \mu \mathrm{g}$ of solute at $T=25^{\circ} \mathrm{C}$. For the cases where RH approaches unity, the aerosol water mass is limited by the saturation water vapor mass, which is a function of temperature. For all other cases $(\mathrm{RH}<1)$, the water mass is limited by the available water vapor and depends on $\mathrm{RH}$.

The use of equivalent solute masses indicates that, in contrast to the calculated single solute molalities, the associated water mass is much less sensitive to uncertainties in solubility. Different hygroscopicities of salt solutes cause (a) a different amount of water uptake at a given $\mathrm{RH}$ and (b) obey a different RHD which determines (i) the RH at which a solution is saturated with respect to the dissolved salt and (ii) the $\mathrm{RH}$ range over which water is associated. Less soluble salts can take up water only over a smaller $\mathrm{RH}$ range, i.e. they follow a higher RHD, so that they precipitate more rapidly from the solution as the water activity deviates from unity.

Note this is very important for aerosol optical and air pollution aspects. For instance, the deliquescence behavior of natural aerosol compounds, which include e.g. $\mathrm{NaCl}$ and $\mathrm{MgCl}_{2}$, changes considerably through the mixing with air pollution, whereby the chlorides are often replaced by nitrates and sulfates which have different RHDs (see Table 3). Air pollution can thus drastically alter the RHD of sea salt aerosol particles, reducing their equilibrium radius, and thus modify their scattering properties and the efficiency by which the particles can grow into cloud droplets. Furthermore, the water mass associated with a certain amount of solute also depends on the salt component. Lighter salt compounds typically bind a larger mass of water. For instance, $1 \mu \mathrm{g}$ of ammonium chloride $\left(\mathrm{NH}_{4} \mathrm{Cl}\right)$ in air pollution fixes approximately the same amount of water as $\mathrm{NaCl}$. According to Fig. $2 \mathrm{~b}$, at $\mathrm{RH}=80 \%$ both would be associated with approximately $30 \mu \mathrm{g}$ of water, while $\mathrm{NaNO}_{3}$ and ammonium nitrate $\left(\mathrm{NH}_{4} \mathrm{NO}_{3}\right)$ would fix only about half that amount, though over a wider range of $\mathrm{RH}$ conditions.

\section{Equilibrium model}

\subsection{EQSAM3}

The theoretical considerations of the previous sections have been incorporated into the third version of the thermodynamic Equilibrium Simplified Aerosol Model, EQSAM3, building on earlier versions of Metzger et al. (2002, 2006). Our aim is to apply EQSAM3 in regional and global chemistry-transport and climate models. It computes the gas/liquid/solid partitioning of all compounds listed in Table 1, whereby only the measured (or estimated) solubility is required as input for each compound. Note that extension with additional compounds can be easily accomplished. Previous EQSAM versions instead used equilibrium constants and tabulated RHD values, and a division in certain chemical domains and sub-domains, similar to other EQMs. EQSAM3 analytically solves the gas/liquid/solid partitioning of almost 100 compounds without further constraints on the aerosol system.

The model set up is as follows:

1. The model is initialized using the thermodynamic data provided in Table 1, whereby the stoichiometric constants for water $\left(v_{w}\right)$ and solute $\left(v_{e}\right)$ can be either prescribed, or $v_{w}$ can be computed online with Eq. (19) from the compound's solubility $\left(W_{S}\right)$, by accounting for its temperature dependency.

2. Since the underlying physical principles are those of an osmotic system, for which the gas-solution analogy is appropriate (see Sect. 2.1.2), we assume that the temperature dependency is described by the gas law, i.e. that it is sufficient for most compounds to divide $W_{s}$ by $T_{o} / T . T_{o}$ is the temperature at which the solubility listed in Table 1 has been measured (for most compounds $\left.T_{o}=298.15[K]\right)$. Note that this describes the temperature dependency of the gas/aerosol system as a whole, since the solubility is used to calculate all other thermodynamic properties $\left(v_{w}, m_{s s}, m_{w}\right.$, RHD).

3. From $v_{w}$ and $v_{e}$ the single solute molalities $\left(m_{s s}\right)$ are derived with Eq. (20) as a function of RH and $T$ for all compounds listed in Table 1.

4. The water mass $\left(m_{w}\right)$ of single solutes and mixed solutions is computed according to Eqs. (22) and (23). Note that Eq. (23) directly follows from the first principles underlying an osmotic system (Sect. 2), i.e. from the 

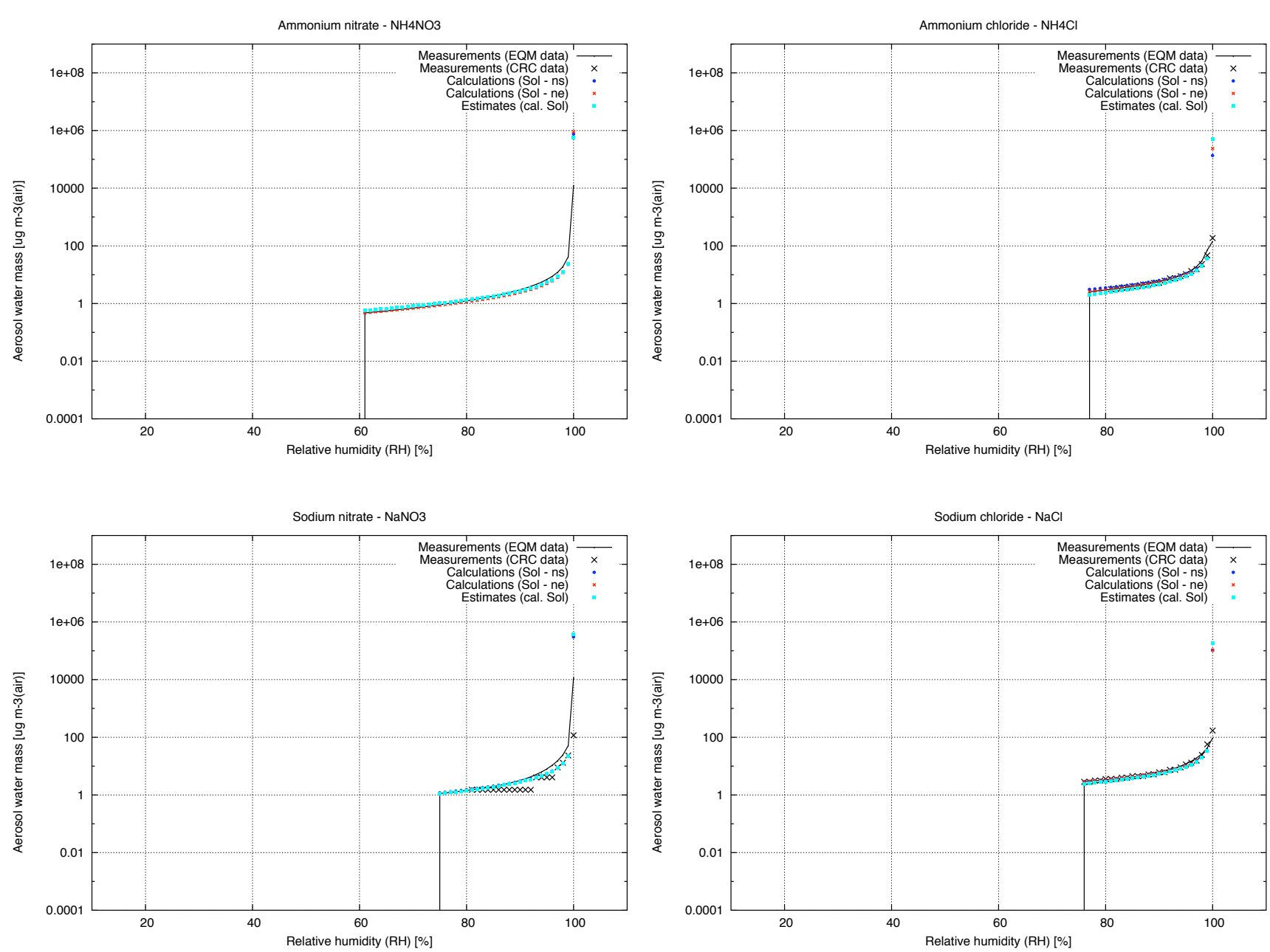

Fig. 2b. Continued.

additivity of partial pressures (implying molar volume additivity for salt compounds), being a consequence of the gas-solution analogy. Note further that Eq. (23) is equivalent to the ZSR-relation, an assumption about the additivity of partial water masses widely used in atmospheric modeling, as empirically established according to Zdanovskii (1948), Stokes and Robinson (1966).

5. The relative humidity of deliquescence (RHD) is calculated from Eq. (21) for single solute solutions and mixed solutions. For the latter the RHD is currently approximated by summarizing $v_{w}, v_{e}$ and $m_{s s}$ over all compounds present in the solution, so that Eq. (21) yields RHD = $\left(\sum_{j=1}^{l_{\text {(aq) }}} v_{e} / \sum_{j=1}^{l_{(\mathrm{aq})}} v_{w} \sum_{j=1}^{l_{(\mathrm{aq})}} m_{s s}^{l_{(\mathrm{aq})}} v_{e} / \sum_{j=1}^{l_{(\mathrm{aq})}} v_{w} / 55.51+1\right)^{-1}$.

For instance, for a mixed solution containing $\left(\mathrm{NH}_{4}\right)_{2} \mathrm{SO}_{4}+\mathrm{Na}_{2} \mathrm{SO}_{4}+\mathrm{NH}_{4} \mathrm{Cl}$, we obtain a mixed solution $\mathrm{RHD}=0.522$, which is lower than the RHDs of the individual compounds (which are according to Table 3, 0.798, 0.939, 0.7659, respectively). The values used in ISORROPIA (Nenes et al., 1998) are 0.54 (mixed solution), and according to Table 2, $0.7997,0.93,0.771$, respectively, for the individual compounds. However, the RHD of mixed solutions could be calculated more explicitly with Eq. (21) if the actual solubilities of solutes in mixed solutions are used to derive $v_{w}$ (and subsequently $m_{s s}, m_{w}$ ) at a given $T-$ a subject that will be investigated further.

6. The reaction order can be either prescribed or determined automatically based on the RHD of the solutes. (a) In case the reaction order is not prescribed, we consider that the reaction order is primarily determined by the solubility. Compounds with a low solubility precipitate from solution already at relatively high $\mathrm{RH}$, so that 
these ions are not available for further reactions. For instance, the solubility of calcium sulfate $\left(\mathrm{CaSO}_{4}\right)$ is very low $(<1 \%)$ which leads to precipitation of $\mathrm{CaSO}_{4}$ at a $\mathrm{RH}$ close to $100 \%$ (Table 2). $\mathrm{CaSO}_{4}$ and other low-soluble salt compounds are therefore regarded as pure solids over the entire RH range. (b) In case the reaction order is prescribed, we rank the ions towards their ability of neutralization, according to the Hofmeister series (Hofmeister, 1888) to account for the degree to which ions bind water (salting-out effect). This increases the effective concentration of other ions (in the remaining "free" water) so that they precipitate, thus releasing low entropy surface water (for details, see e.g. http://www.lsbu.ac.uk/water/).

We assume the following neutralization order for the ions of the single solutes currently considered, whereby the ions to the left become preferentially neutralized:

$$
\begin{aligned}
& \text { - Anions: } \mathrm{PO}_{4}^{3-}>\mathrm{SO}_{4}^{2-}>\mathrm{HSO}_{4}^{-}>\mathrm{NO}_{3}^{-}> \\
& \mathrm{Cl}^{-}>\mathrm{Br}^{-}>\mathrm{I}^{-}>\mathrm{CO}_{3}^{2-}> \\
& \mathrm{HCO}_{3}^{-}>\mathrm{OH}^{-}>\mathrm{CHO}_{2}^{-}> \\
& \mathrm{C}_{2} \mathrm{H}_{3} \mathrm{O}_{2}^{-}>\mathrm{C}_{2} \mathrm{O}_{4}^{2-}>\mathrm{C}_{6} \mathrm{H}_{5} \mathrm{O}_{7}^{3-} \\
& \\
& \text { - Cations: } \mathrm{Fe}^{3+}>\mathrm{Mg}^{2+}>\mathrm{Ca}^{2+}>\mathrm{Na}^{+}> \\
& \mathrm{K}^{+}>\mathrm{NH}_{4}^{+}>\mathrm{H}^{+}
\end{aligned}
$$

Note that this neutralization order is preliminary. Measurements are required for validation.

7. Based on the reaction order (prescribed or automatically determined for given $T, \mathrm{RH}$ ) the compounds in the solution and the non-neutralized "free" ions are computed. The $\mathrm{H}^{+}$concentration and the $\mathrm{pH}$ of the solution is explicitly calculated starting from electroneutrality, by accounting for the auto-dissociation of water and optionally for atmospheric $\mathrm{CO}_{2}$. Based on the RHD of the single solutes in the (mixed) solution liquid/solid partitioning is calculated, whereby all compounds for which the RH is below the RHD are assumed to be precipitated, so that a solid and liquid phase can co-exist.

8. We distinguish between the wetting and drying process of the particle, following a hysteresis loop. While for the former case (lower tail of the hysteresis loop) ambient aerosols are wetted as the RH increases above the deliquescence of salt compounds in the solid phase (by which more hygroscopic compounds take up water first, i.e. at a lower RH), the latter case (upper tail of the hysteresis loop) is calculated by considering the compounds efflorescence RHs, whereby the particle is assumed to be a pure solid if all salt compounds are crystallized. The RH at which salt compounds crystallizes can be much lower than its deliquescence RH. This directly results from the fact that in case the RH decreases below the RHD the compound precipitates out of the solution, until its solubility product is re-establised having the same water activity as at the RHD, but with less water according to the lower solute mass. This process continues until the solute has been completely precipitated, whereby the solute can be assumed to be crystallized if no water is left for hydration. This exactly happens at the efflorescence $\mathrm{RH}_{\mathrm{cr}}$. Depending on the solute hygroscopicity, the final particle crystallization can occur at a very low RH, below $10 \%$.

9. Efflorescence humidities $\left(\mathrm{RH}_{\mathrm{cr}}\right)$ are calculated with Eq. (21). Instead of the saturation molality $\left(m_{s s, \text { sat }}\right)$, we use the actual (supersaturation) molality to calculate the water uptake as a function of $\mathrm{RH}$. Expressing the molality in terms of the remaining solute mass fraction similar to Eq. (18c) but with $m_{s s}=1000 / M_{s}\left(1 / w_{s}-1\right)$, we can calculate upon substitution into Eq. (21) the humidity at which the solute is completely precipitated (crystallized) from $\mathrm{RH}_{\mathrm{cr}}=1-\left[\left(\frac{v_{e}}{v_{w}}\left[1000 / M_{s}\left(1 / \mathrm{w}_{\mathrm{s}}-1\right)\right]^{\frac{v_{e}}{v_{w}}} / 55.51\right)+1\right]^{-1}$. For instance, for three pure salt compounds (1) $\mathrm{NH}_{4} \mathrm{NO}_{3}$, (2) $\mathrm{NH}_{4} \mathrm{HSO}_{4}$ and (3) $\left(\mathrm{NH}_{4}\right)_{2} \mathrm{SO}_{4}$, we obtain the following efflorescence humidities $\quad \mathrm{RH}_{\mathrm{cr}, 1}=0.11(0.10), \quad \mathrm{RH}_{\mathrm{cr}, 2}=0.07(0.02) \quad$ and $\mathrm{RH}_{\mathrm{cr}, 3}=0.34(0.39)$, respectively; values in brackets are reported in the literature by ten Brink et al. (1996) for $\mathrm{NH}_{4} \mathrm{NO}_{3}$, and Tang and Munkelwitz (1994) for the two other salts.

10. Gas/liquid partitioning is calculated for all (semi-) volatile compounds (first row of Table 1) except phosphoric and sulfuric acid, which are treated as nonvolatile due to their very low vapor pressures.

11. For (semi-) volatile compounds such as $\mathrm{NH}_{4} \mathrm{NO}_{3}$ and $\mathrm{NH}_{4} \mathrm{Cl}$ activity coefficients are used. Non-volatile compounds remain in the particulate phase independent of the solute concentration, whereby the liquid/solid partitioning is merely determined by the solute solubility. Since the water mass is proportional to the solute mass (at a given $T, \mathrm{RH}$ ) activity coefficients are not needed for non-volatile compounds. For (semi-) volatile compounds, which can be driven out of the aerosol in the gas phase, activity coefficients are needed and computed from Eqs. (14-16) and (20), whereby we account for the charge density of the solution (Metzger et al., 2002a). The mean ion-pair activity coefficients of volatile compounds are thus obtained in EQSAM3 from $\gamma_{s, j}^{ \pm}=\left(\mathrm{RH}^{-\frac{v_{w}}{v_{e}}} /\left[v_{w} / v_{e} 55.51(1 / \mathrm{RH}-1)\right]^{\frac{v_{w}}{v_{e}}}\right)^{\frac{2}{\xi_{s, j}}}$, whereby we divide the mean ion-pair activity coefficient by the solute's density $\left(\rho_{s, j}\right)$ to obtain the the mean molar binary activity coefficient $\gamma_{s(\text { molar }), j}^{ \pm}=\gamma_{s, j}^{ \pm} / \rho_{s, j}$ $\left[1\left(\mathrm{H}_{2} \mathrm{O}\right) / \mathrm{mol}(\right.$ solute) $)$, and additionally multiply it by the density of water $\left(\rho_{w}\right)$ to obtain it on the molal scale $\gamma_{s(\text { molal }), j}^{ \pm}=\gamma_{s, j}^{ \pm} \times \rho_{w} / \rho_{s, j} \quad\left[\mathrm{~kg}\left(\mathrm{H}_{2} \mathrm{O}\right) / \mathrm{mol}(\right.$ solute $\left.)\right]$. 

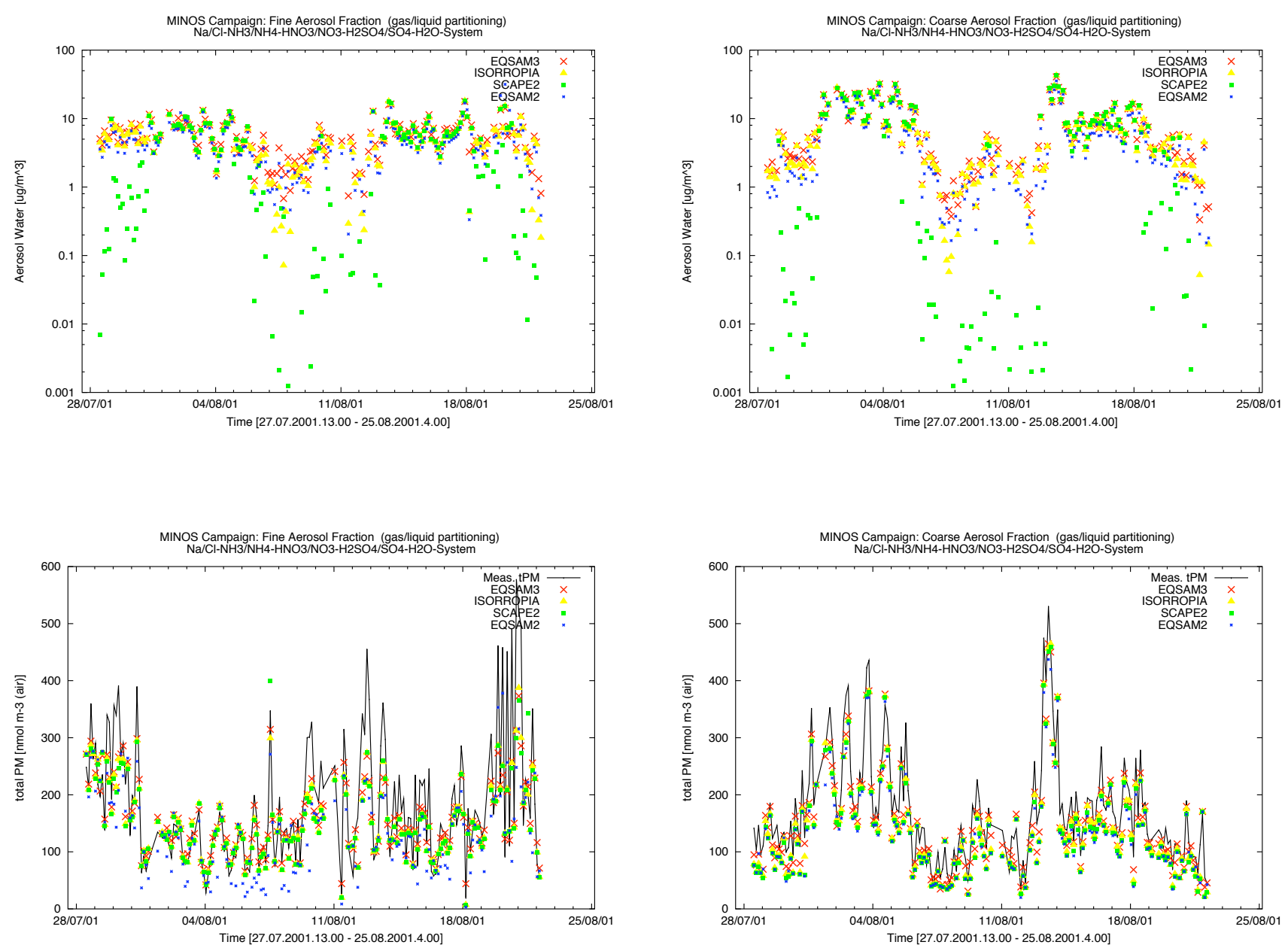

Fig. 3a. Mixed solution properties and model comparison for the MINOS campaign (Metzger et al., 2006). (a) Aerosol water (top), total number of moles of particulate matter (PM) (bottom) for fine (left) and coarse mode (right); (b) fine mode: total aerosol mass (top, left), total solid mass (top, right), aerosol ammonium nitrate activity coefficient (bottom, left), $\mathrm{pH}$ (bottom, right); (c) residual gaseous ammonia (top, left), residual gaseous nitric acid (top, right), aerosol fine mode ammonium (bottom, left), aerosol fine mode nitrate (bottom, right). All panels show time series for the period 28 July-25 August 2001 of the ammonium/sulfate/nitrate/chloride/sodium/water system, comparing measurements (black solid line) and results of EQSAM3 (red crosses), ISORROPIA (yellow closed triangles), SCAPE2 (green closed squares), EQSAM2 (blue, small crosses). Note that this model comparison and chemical system is identical to the model comparison for chemical system F2/C2 of Metzger et al. (2006) with EQSAM2 denoted as EQSAM2*.

Activity coefficients of the corresponding cations $\left(\gamma_{s+}\right)$ and anions $\left(\gamma_{s_{-}}\right)$can be computed from Eq. (16), assuming $\gamma_{s+}^{v_{e}^{+}}=\gamma_{s-}^{v_{e}^{-}}$in accord with Eq. (15).

$\xi_{s, j}$ expresses the effective ion charge of the hydrated/dissociated solute relative to the charge of the water ions involved in the hydration (which act as a dielectricum reducing the electrical forces of the solute cation and anions). Thus, $\xi_{s, j}=N_{ \pm} v_{e} / z_{s, j}^{ \pm}$with $z_{s, j}^{ \pm}=z_{s,+, j}^{v_{e}^{+}}+z_{s,-, j}^{v_{e}^{-}}$the total charge of the ion-pair of the $j$ th-compound with $N_{ \pm}=k_{ \pm}^{k_{ \pm}}$, whereby $k_{ \pm}=2$ and accounts for the fact that 2 moles of water are consumed for each mole of $\mathrm{H}_{3} \mathrm{O}^{+}$produced (assuming electroneu- trality for dissociation reactions). For instance, for (semi-) volatile, single charged compounds such ammonium nitrate $\left(j=\mathrm{NH}_{4} \mathrm{NO}_{3}\right)$, where $z_{s, j}^{ \pm}=1_{e}^{v_{e}^{+}}+1^{v_{e}^{-}}=2$, we obtain with the thermodynamic data provided in Table 1 (at $T=298.15[\mathrm{~K}]), \rho_{w}=0.997\left[\mathrm{~g} / \mathrm{cm}^{3}\right], \rho_{s}=1.72$ $\left[\mathrm{g} / \mathrm{cm}^{3}\right], v_{e}=1.97, W_{s}=68.05[\%]$ and $v_{w}=1.839(\mathrm{de}-$ rived from $W_{s}$ by Eq. 19) for $\xi_{s, j}=4 \times 1.97 / 2=3.94$ and for the mean molal binary activity coefficient at saturation ( $\mathrm{RH}=\mathrm{RHD}=0.6067$ according to Eq. 21), $\gamma_{s(\text { molal }), \mathrm{NH}_{4} \mathrm{NO}_{3}}^{ \pm}=\gamma_{s, j}^{ \pm} \times \rho_{w} / \rho_{s, j}=0.239 \times 0.997 / 1.72=$ $0.1389\left[\mathrm{~kg}\left(\mathrm{H}_{2} \mathrm{O}\right) / \mathrm{mol}\right.$ (solute)]. For a comparison, Hamer and Wu (1972) give a value of 0.131, which is discussed in Mozurkewich (1993). 

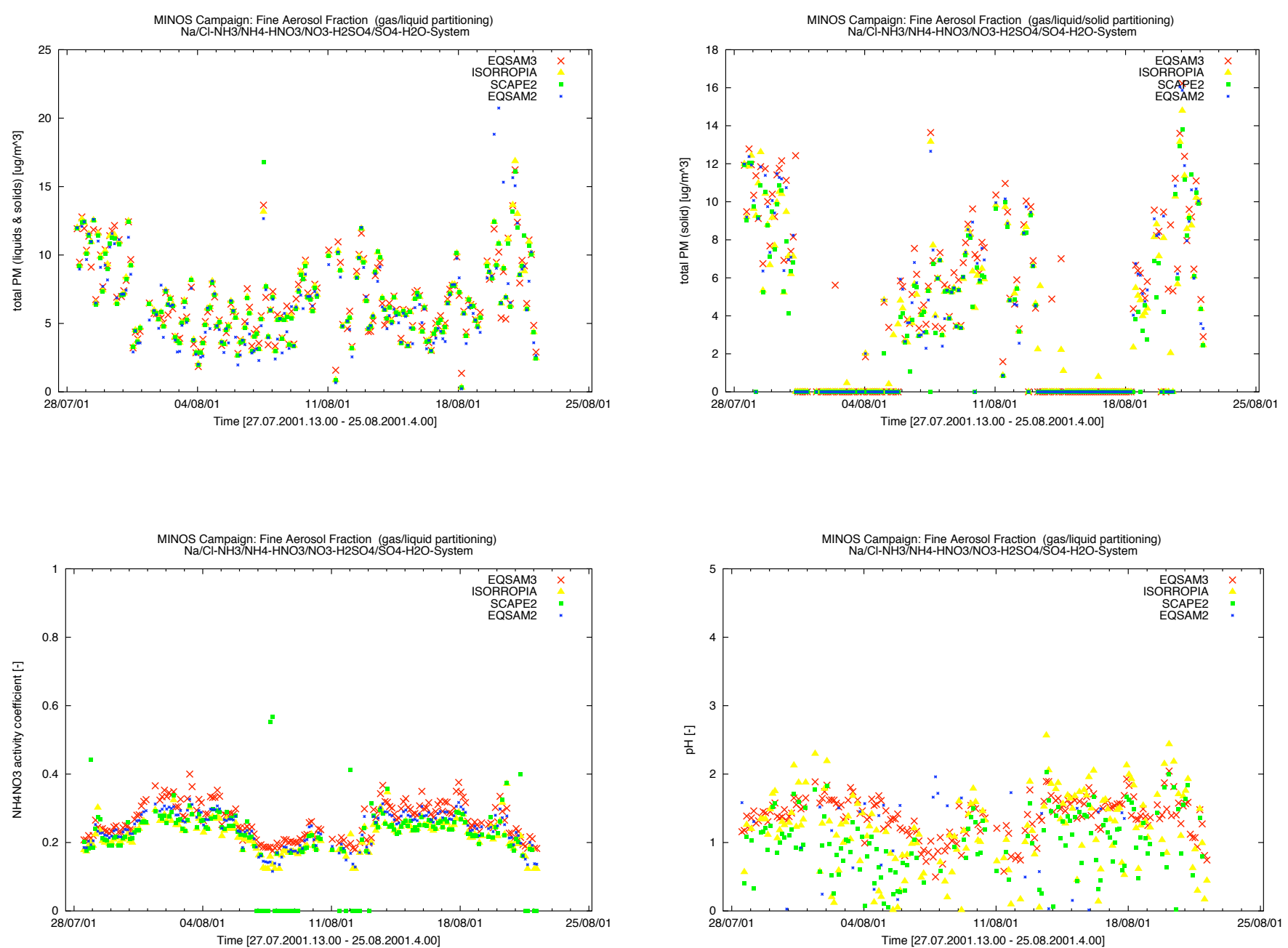

Fig. 3b. Continued.

12. The residual gases and acids (first row of Table 1) are computed from the remaining cations and anions, whereby (semi-)volatile acids are assumed to remain in the gas phase if not neutralized, or taken up directly from the aqueous solution (which however yields only small amounts relative to the total particulate matter).

13. Non-electrolyte solutes (last row of Table 1) are, except ammonia $\left(\mathrm{NH}_{3}\right)$, not directly considered for the determination of the reaction order, nor are they assumed to be involved in neutralization reactions. However, they contribute to the aerosol mass, and as long as they remain hydrated also to the aerosol water mass.

14. Various aerosol properties can be computed and stored for diagnosis, including aerosol properties that are both difficult to measure and to model, such as the solution $p H=-\log \sum_{j=1}^{l_{\text {(aq) }}}\left(n_{s,+, j} / m_{w}\right)$, and the ionic strength of binary and mixed solutions $Z=0.5 \times\left(Z_{s,+}+Z_{s,-}\right) / m_{w}$,

with $Z_{s,+}=\sum_{j=1}^{l_{(\mathrm{aq})}} z_{s,+, j}^{v_{e}^{+}}$and $Z_{s,-}=\sum_{j=1}^{l_{\text {(aq) }}} z_{s,-, j}^{v_{e}^{-}}$the total charge of cations and anions, respectively. Aerosol properties such as mass and number of moles, and the associated water mass can be stored for each compound yielding listings similar to Table 3 . Additionally, the total particulate matter (PM), including solids and ions, can be expressed as both the total number of moles, $\mathrm{PM}=\sum_{j=1}^{l_{\text {(aq) }}} n_{s(\mathrm{aq}), j}+\sum_{j=1}^{l_{\text {(cr) }}} n_{s(\mathrm{cr}), j}$, the total mass, $\mathrm{PMt}=\sum_{j=1}^{l_{\text {(aq) }}} n_{s(\mathrm{aq}), j} M_{s, j}+\sum_{j=1}^{l_{\text {(cr) }}} n_{s(\mathrm{cr}), j} M_{s, j}$, respective the total dry mass $\mathrm{PMs}=\sum_{j=1}^{l_{(\mathrm{cr})}} n_{s(\mathrm{cr}), j} M_{s, j}$, whereby mass and water fractions of all individual compounds are explicitly summarized (for PMt and PMs using the individual molar masses $M_{s, j}$; aerosol water according to Eq. (23)). 

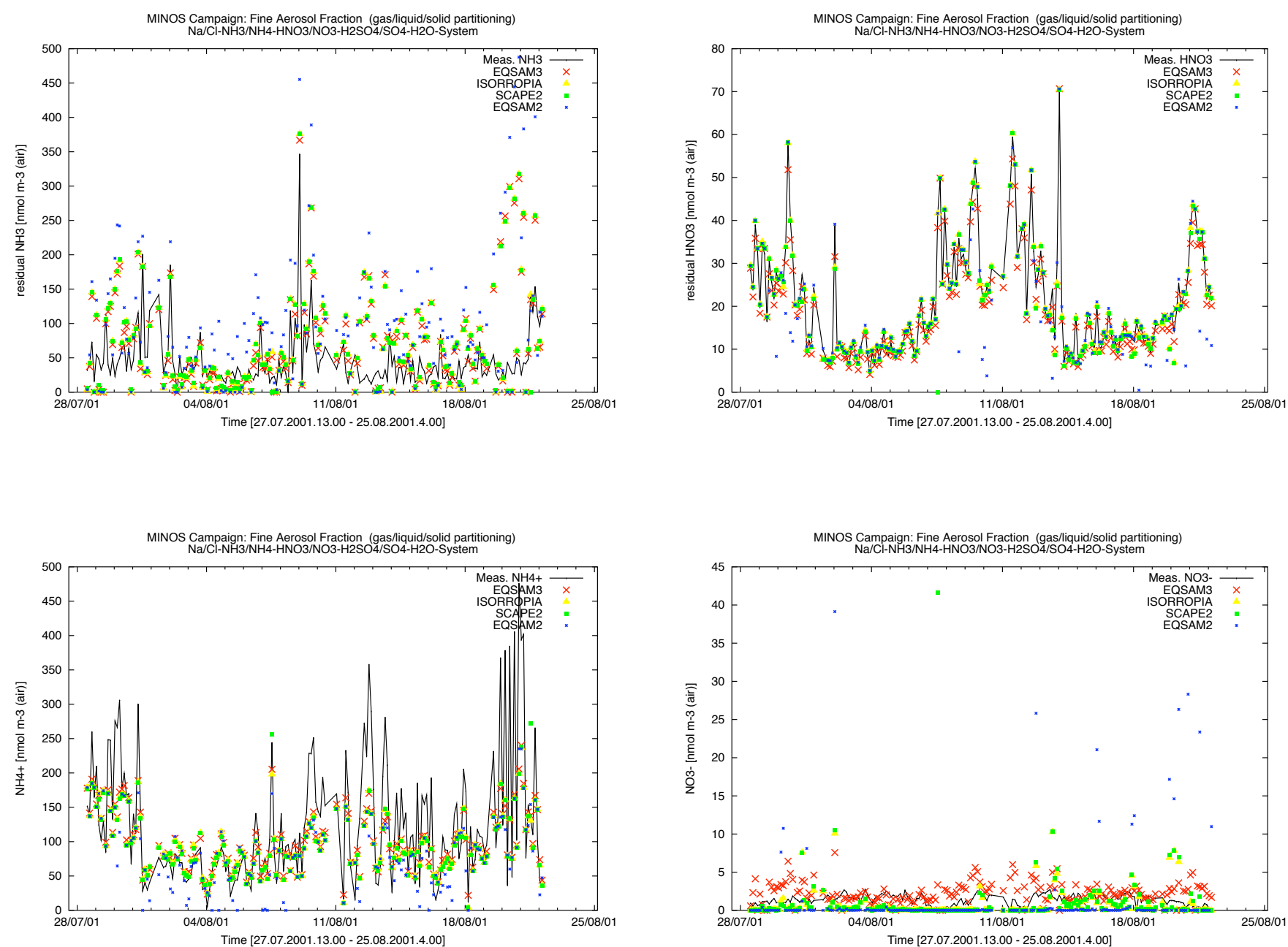

Fig. 3c. Continued.

Note that the structure of EQSAM2 (Metzger et al., 2006) has been adopted also in EQSAM3, however, EQSAM2 was not based on solubilities. Instead it used equilibrium constants and prescribed RHDs as listed in Metzger (2000), and activity coefficients for volatile compounds according to Metzger et al. (2002). The underlying physical principles are nevertheless the same. An example application of EQSAM2 and EQSAM3 is given in the next section. Both model versions are available for the scientific community upon request.

\subsection{Comparison with measurements}

We apply EQSAM3 to measurements obtained from MINOS (Mediterranean INtensive Oxidant Study) in Crete in the period 27 July to 25 August 2001 (Lelieveld et al. 2002), by extending the model-data comparison of Metzger et al. (2006). For a general description of the measurements and the comparison set-up we refer to that article. To compare EQSAM3 with other EQMs (EQSAM2, ISORROPIA, SCAPE2), we apply all models to mixed solutions at the same level of complexity, by which we focus on the chemical system F2/C2 as defined in Metzger et al. (2006), i.e. the ammonium/sulfate/nitrate/chloride/sodium/water system.

Figure 3 shows 4-weekly time series of various model calculated mixed solution properties; observations are included where available. Figure $3 \mathrm{a}$ shows that the total fine and coarse mode aerosol water mass is consistently predicted by the EQMs, assuming metastable aerosols (gas/liquid partitioning) with EQSAM3, EQSAM2 and ISORROPIA. Particularly the results of EQSAM3 and ISORROPIA are rather close; SCAPE2 deviates most significantly for the dry periods because the assumption of metastable aerosols breaks down. Instead, SCAPE2 calculates the full gas/liquid/solid partitioning. These results (in particular the deviations) provide an indication of the relative importance of deliquescence thresholds (RHDs), crucial for the liquid-solid partitioning. 
All model predictions of the total number of moles in the solid and aqueous phase (particulate matter, PM) are in good agreement for both the fine and coarse mode. EQSAM2 shows relatively largest deviations for the fine mode. The results of EQSAM3 appear to be closest to ISORROPIA, which is coded to achieve the highest possible degree of numerical accuracy (though being much more CPU-time expensive than EQSAM3).

Focusing further on the fine mode, Fig. $3 \mathrm{~b}$ shows that all models consistently predict the total aerosol mass (total PM) and, because all models account for the full gas/liquid/solid partitioning, also the associated dry aerosol mass fraction. Note that the total PM in terms of mass is more sensitive to failures in predicting the aerosol composition than the total PM in terms of moles, since each individual molar mass of the compounds (in the solid and liquid phase) is explicitly accounted for (summarized). Again, the relatively largest deviations can be attributed to differences in the RHD calculations; except SCAPE2 all models account for the RHD of mixed solutions, whereby EQSAM2 uses a combination of RHD values from both ISORROPIA and SCAPE2, i.e. mutual deliquescence RHDs of ISORROPIA when available, and RHDs of SCAPE2 for all mineral compounds (not considered in ISORROPIA). EQSAM3 computes all RHDs (of single solute or mixed solutions) from Eq. (21), as described above. Figure $3 b$ furthermore shows that even the predictions of very sensitive aerosol properties such as the mean binary activity coefficients (shown is the one of ammonium nitrate in the mixed solution) and the solution $\mathrm{pH}$ are in general agreement.

Figure $3 c$ demonstrates that all EQMs predict the residual gaseous ammonia and nitric acid and the corresponding aerosol ammonium and nitrate. Especially the calculations of the lowest measured aerosol nitrate concentrations are most accurate with EQSAM3, being quite sensitive to the activity coefficient of ammonium nitrate. Note that the models do not necessarily need to be in agreement with all observations for ammonia/ammonium. The reason is that mineral cations and organic acids are omitted in the EQM comparison because ISORROPIA does not account for these compounds. Metzger et al. (2006) showed that the presence of ammonium in the aerosol phase is dependent on the presence of organic acids (e.g. from biomass burning) in cases where alkali-cations (e.g. mineral dust) are present in excess of inorganic acids. In fact, the consistent inclusion of alkali-cations and organic acids is important for the gas/aerosol partitioning of reactive nitrogen compounds for both fine and coarse mode particles. In contrast to the cation ammonium, the anion nitrate is less affected in the fine mode than in the coarse mode, so that the aerosol nitrate predictions of EQSAM3, which are closest to the observations for this sensitive case, also give evidence for its applicability.

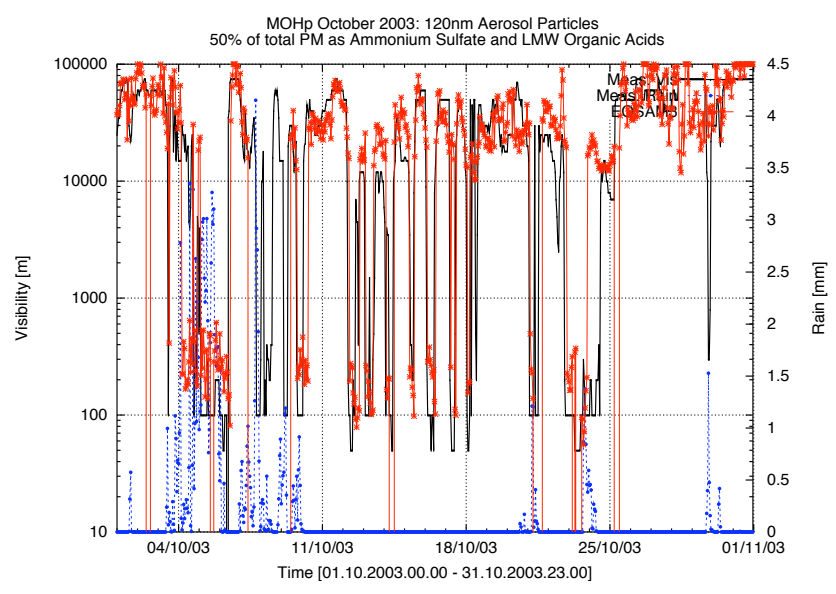

Fig. 4. Outlook: Visibility predictions with EQSAM3 (red) assuming $120 \mathrm{~nm}$ particles with $50 \%$ ammonium sulfate and low molecular weight (LMW) organic acids. Visibility measurements of the Meteorological Observatory Hohenpeißenberg (MOHp), Germany are shown for October 2003 in black (solid line), precipitation (right y-axes) in blue (dotted).

\subsection{Application outlook}

To indicate the potential of our theoretical considerations and implications for atmospheric pollution and climate modeling, we present in this section a preview of some applications in progress with EQSAM3, including visibility predictions and aerosol-cloud interactions. For details we refer to future publications.

\subsubsection{Visibility predictions}

Under humid conditions, hygroscopic aerosol particles can substantially reduce atmospheric visibility. Figure 4 presents visibility predictions with EQSAM3, compared with observations at the Meteorological Observatory Hohenpeißenberg (MOHp), Germany, for October 2003. The "translation" of PM concentration and particle size into visibility, based on aerosol optical parameters, will be described elsewhere.

Visibility calculations based on $120 \mathrm{~nm}$ sized particles composed of $50 \%$ ammonium sulfate (AS) and 50\% of low molecular weight (LMW) organic acids (e.g. formic and acetic acid) are comparable to the observations, while same or smaller sized particles composed out of either only AS or organics show poorer agreement, in particular for high and low visibility (not shown). Remarkably, even in cases where precipitation was observed the model predicts low visibility. This provides a first indication that there exists overlap between conditions of high aerosol water and cloud formation.

\subsubsection{Global applications}

Our preliminary global modeling applications focus on the role of the aerosol water mass, being highly relevant for 


\section{E5M1-EQSAM3}
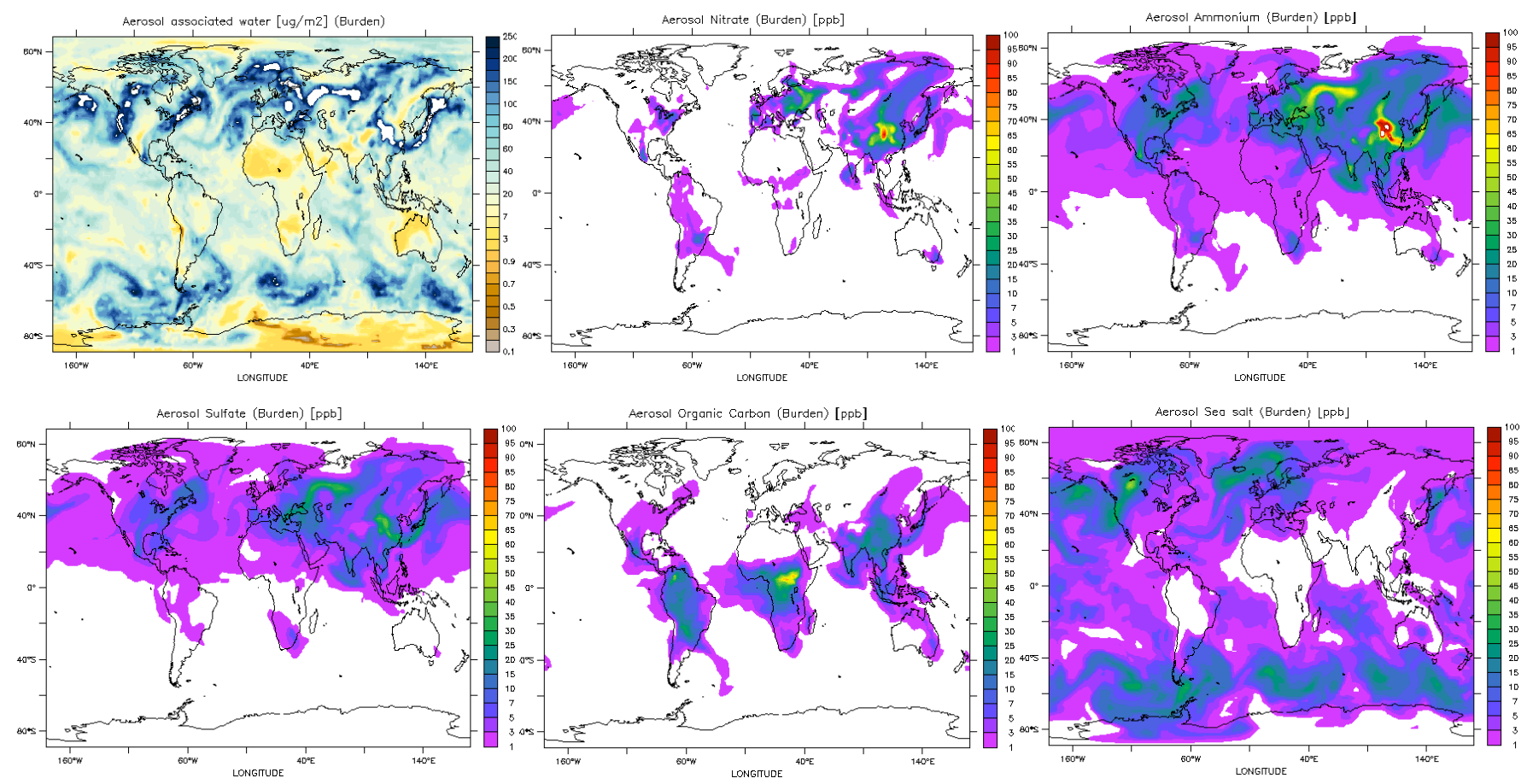

Fig. 5. Outlook: Global aerosol distributions for GMT noon 9. September 2000 (snap shot): (a) Atmospheric burden (fine mode): Aerosol water mass $(\mathrm{AW})$ in $\left[\mu \mathrm{g} / \mathrm{m}^{2}\right]$, aerosol nitrate, ammonium, sulfate, primary organics and sea salt (from top left to bottom right); AW (b) tropospheric burden; (c) AW upper troposphere lower stratosphere (UTLS); (d) cloud coverage derived from AW; (e) cloud cover comparison for the US: ECHAM5 standard calculations (top left), AW based (regional selection of panel d), satellite observations (GEOS, channel 4). The global calculations were obtained with the chemistry-climate model E5M1 (http://www.messy-interface.org).

climate forcing estimates. Note that present climate models that include aerosols do not explicitly calculate aerosol water. Here we aim to show that EQSAM3 can provide a computationally efficient alternative that does not only accurately simulates the aerosol chemical composition but also the most abundant aerosol species, water.

We apply the general circulation model ECHAM5 (Roeckner et al., 2003) at T63 ( 1.9 degree), resolution, extended with the comprehensive Modular Earth Submodel System (MESSy) to account for atmospheric chemistry (Jöckel et al., 2006). The model will be abbreviated in the following as E5M1. It has been additionally extended by the MESSy version of EQSAM (http://www.messy-interface.org/), which accounts for 7 aerosol modes, including four soluble and three insoluble: nucleation, aitken, accumulation and coarse, whereby the latter three modes are used to distinguish between primary insoluble and soluble aerosol species such as black carbon or certain mineral dust compounds (similar as in Vignati et al., 2004). Details will be provided in a followup publication.

\section{Various aerosol species}

Figure 5a presents a "snapshot" of the model results for 9 September 2000 (12:00 GMT) by showing the spatial distribution (vertical integral) of various fine mode aerosol species, including aerosol water mass $\left[\mu \mathrm{g} / \mathrm{m}^{2}\right]$, aerosol nitrate, ammonium, sulfate, organic carbon, and sea salt $\left[\mathrm{ppb}_{\mathrm{v}}\right]$ (from top left to bottom right). While certain aerosol species such as nitrates and organics are largely confined to continental areas, associated with the localized emission sources, other species such as ammonium and sulfate show much wider dispersion. Fine mode ammonium is highly correlated with sulfate, and can be transported over long distances. Nitrate compounds are volatile and they are also found on coarse mode particles (not shown), such as sea salt and mineral dust, which are more efficiently deposited.

Figure 5a shows that the spatial distribution of aerosol water $(\mathrm{RH}<0.95)$ strongly correlates with that of sea salt, sulfate and ammonium, and that at this arbitrary RH limit the aerosol water mass already dominates the total aerosol load. Figure $5 \mathrm{~b}$ shows the tropospheric aerosol water mass, while Fig. $5 \mathrm{c}$ presents the corresponding aerosol water in the upper troposphere - lower stratosphere (UTLS) region. These 
figures are complementary and illustrate the dependence on synoptic weather conditions. Atmospheric dynamics determine the temperature and the water vapor mass available for condensation, which subsequently determines the amount of aerosol water.

\section{Cloud cover}

In a case for which we do not limit the RH to $95 \%$, as in the previous example, aerosol water strongly increases when $\mathrm{RH}$ approaches unity. This directly follows from the thermodynamic principles described in Sect. 2 and can be best seen from Eq. (5). Note that the aerosol water mass calculated from Eq. (23) involves Eq. (20), based on Eq. (5). However, applying Eq. (5) to atmospheric conditions requires that the condensation of water vapor is limited by the availability of water vapor which is determined by $\mathrm{RH}$ and the saturation water vapor. Thus we use the following thermodynamic constraints to limit the condensation of water vapor, and hence the aerosol water mass for atmospheric applications:

1. Limiting the amount of condensing water by the availability of water vapor; this encompasses all conditions with $\mathrm{RH}<1$.

2. Limiting the amount of condensing water by the amount of water vapor constrained by the saturation water vapor mass, being only a function of temperature; thus encompassing cases with $\mathrm{RH} \geq 1$.

3. Adjusting the water vapor concentration for the condensed amount of water vapor (aerosol water mass), which becomes important for all cases where RH approaches unity; in particular for the UTLS region, but also for all regions where aerosol water overlaps with cloud water/ice presence.

Subsequently, we directly compute the cloud cover from the total aerosol load (including water) by assuming total coverage of the relevant model grid cells (i.e. a cloud cover fraction of unity) in case the aerosol load exceeds an amount that is determined by the saturation water vapor mass at a given temperature. The cloud cover therefore depends on:

1. The amount of total particulate aerosol matter (PMt); according to Eqs. (22), (23) the aerosol water mass is proportional to PMt (illustrated in Fig. 1b).

2. The type of PMt; according to Eqs. (20), (21) the aerosol water mass depends on the type of solute (illustrated in Figs. 2a, b).

3. The temperature dependent saturation water vapor mass that determines the maximum amount of water available for condensation leading to hygroscopic growth of aerosols; hazy conditions are favored by high aerosol load (dominated by hygroscopic salt solutes) and low (b)
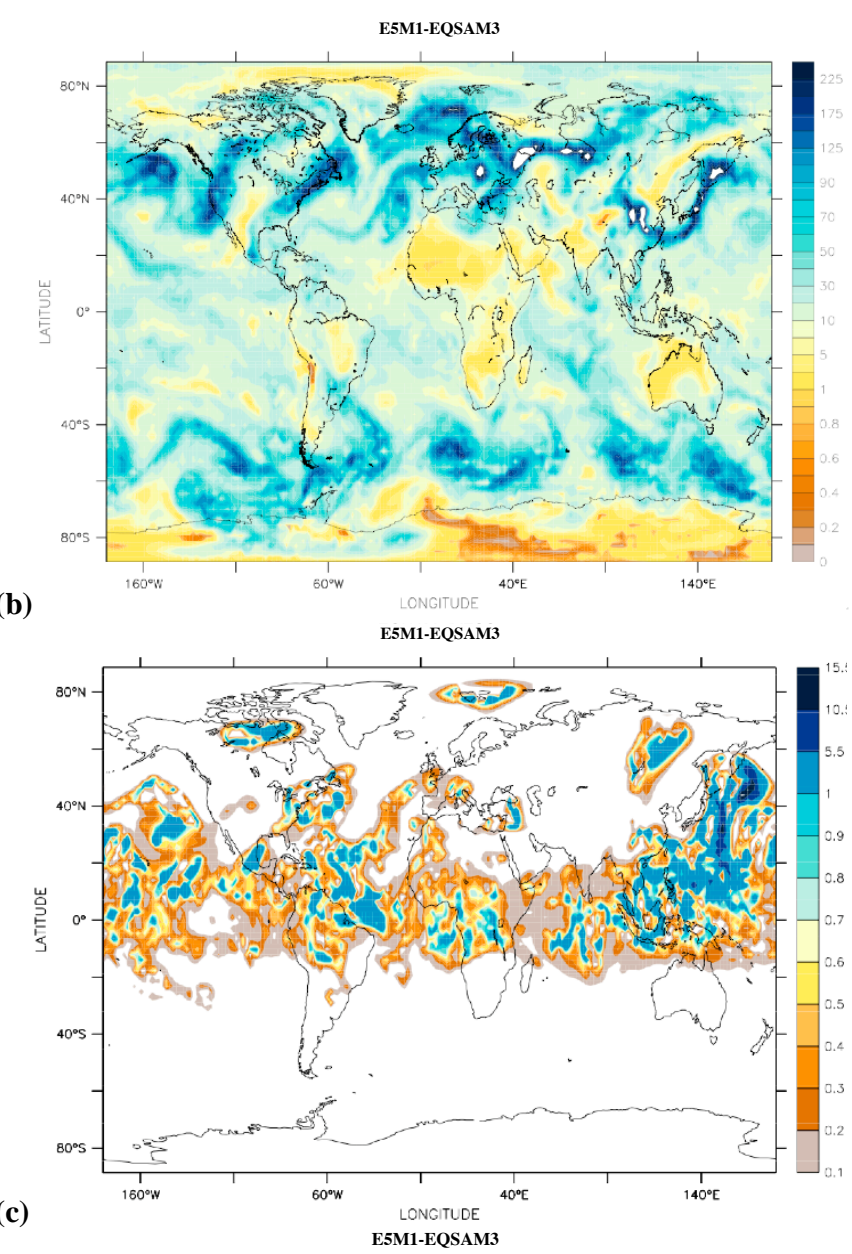

(c)

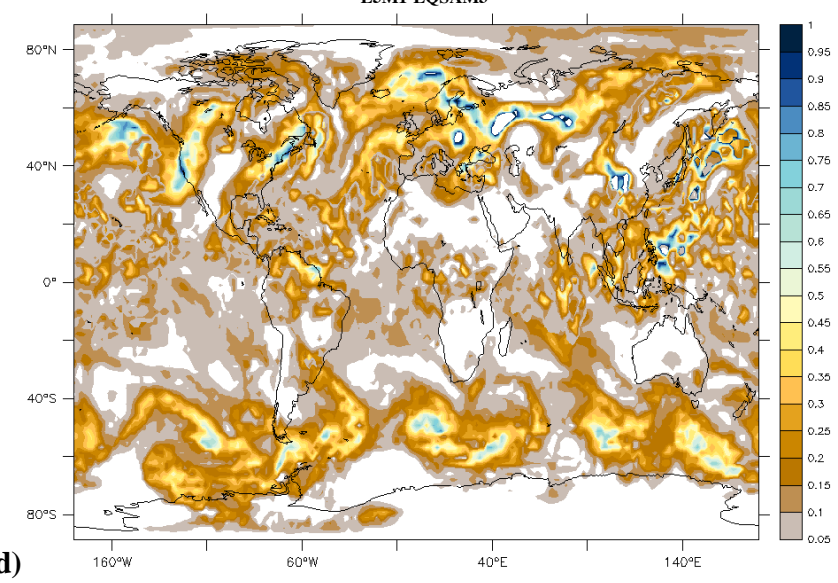

Fig. 5. Continued.

temperatures. When the ambient temperature drops below the dew point temperature, the water vapor concentration exceeds the amount of water vapor that can be taken up by the air so that it is saturated with respect to water vapor; additional water vapor directly condenses, which leads to fog, haze and clouds. Note that this 

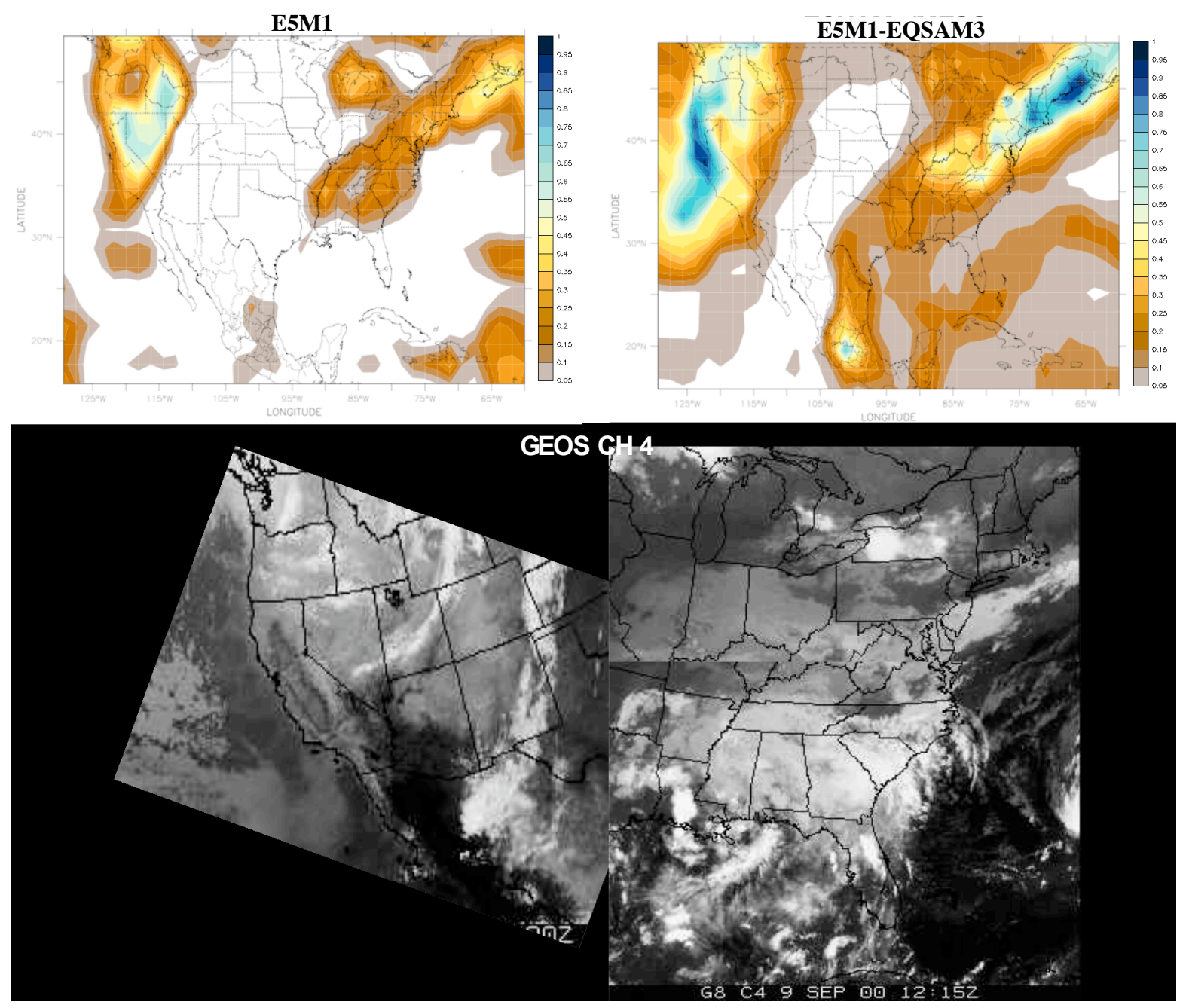

(e)

Fig. 5. Continued.

temperature dependency implicitly accounts for all aspects of atmospheric dynamics (to the extent resolved by the model), including moisture and temperature fluctuations in the UTLS.

Figure 5d shows that the cloud cover coincides with the aerosol water mass following the synoptic pattern shown in Figs. 5a-c, since the cloud cover has been diagnosed from the total aerosol load as described above (without considering aerosol-cloud and radiation feedbacks). Figure 5e shows a regional comparison of these results with GEOS satellite observations for the USA. The lower panel shows the cloud cover as observed from space (GEOS channel 4), while the upper left panel shows the cloud cover prediction of the base E5M1 model; in the upper right panel the cloud cover is based on the EQSAM3 water uptake calculations. This qualitative comparison with satellite observations indicates that especially optically thin clouds are better resolved if aerosol water is accounted for. Note that the cloud cover computed with the combination of E5M1 and EQSAM3 is higher over the region of Florida and southern California / northern Mexico than with the original E5M1 cloud cover scheme, and compare favorably with GEOS. This issue deserves more attention, including additional model tests and optimization, and will be considered in future work.

\section{Cloud ice}

Our results thus indicate that especially optically thin clouds may be described by aerosol water model predictions. If aerosols are treated comprehensively, as described above, there is actually no principal physical difference between aerosol water, cloud water and cloud ice - the subdivision is to some degree arbitrary as determined by the droplet size. 
E5M1 - Total vertically integrated $\mathrm{Cl}\left[\mathrm{g} / \mathrm{m}^{2}\right]$

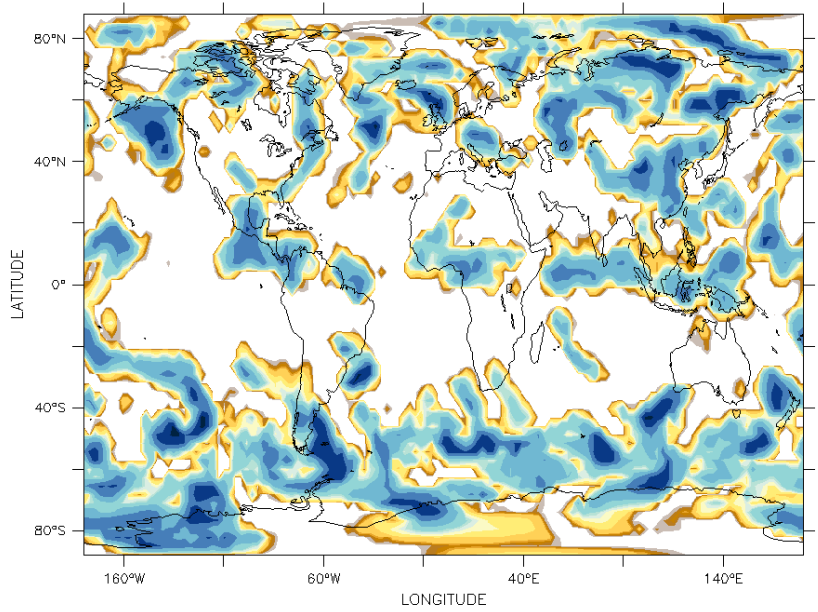

E5M1 - UTLS vertically integrated $\mathrm{Cl}\left[\mathrm{mg} / \mathrm{m}^{2}\right]$

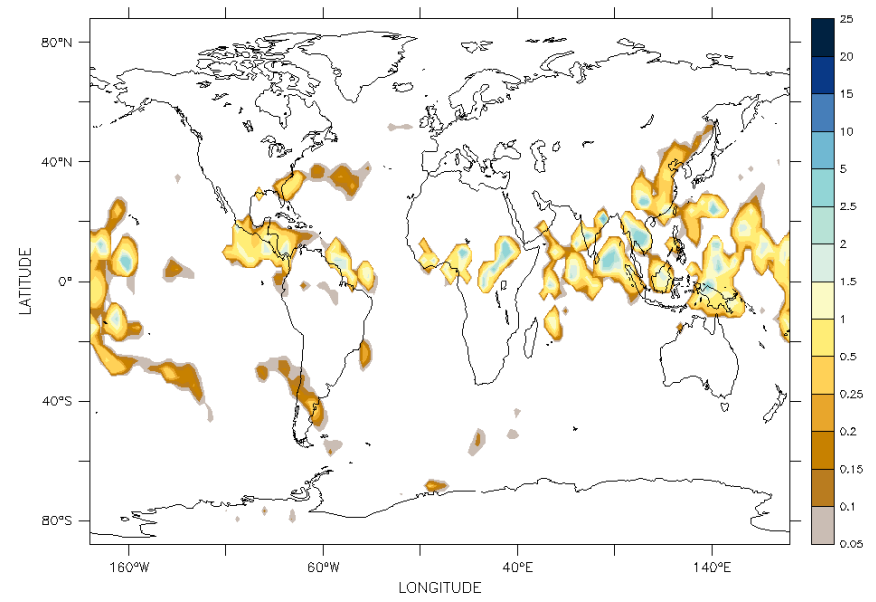

E5M1-EQSAM3 - Total vertically integrated $\mathrm{Cl}\left[\mathrm{g} / \mathrm{m}^{2}\right]$

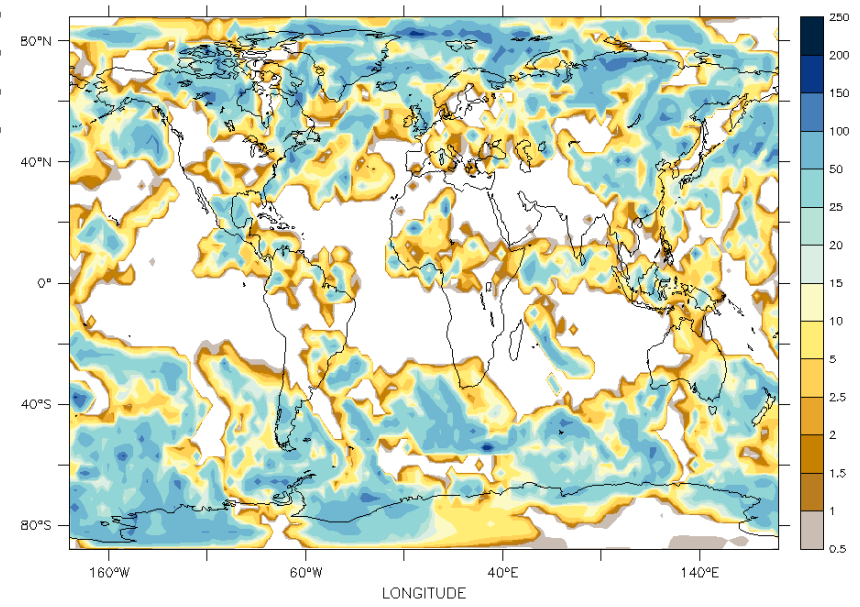

E5M1-EQSAM3 - UTLS vertically integrated $\mathrm{Cl}\left[\mathrm{mg} / \mathrm{m}^{2}\right]$

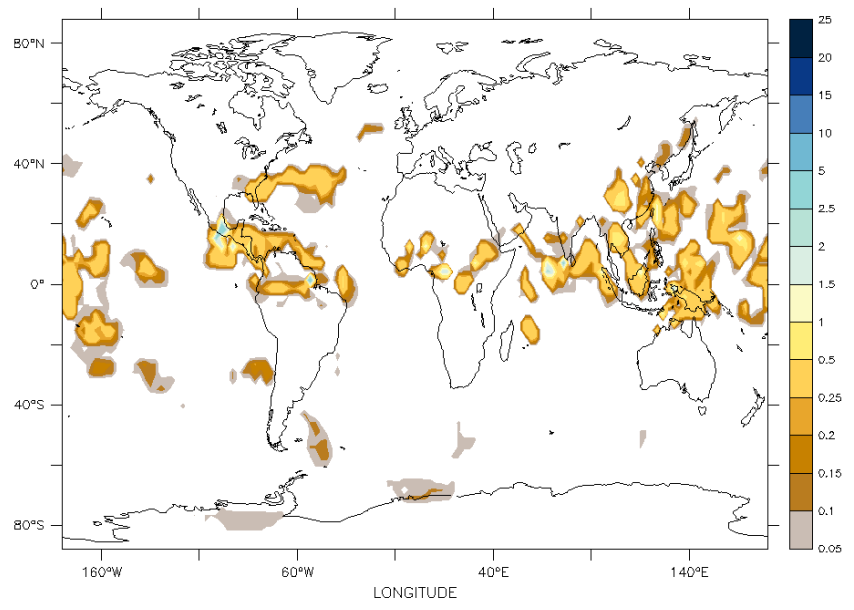

Fig. 6. Comparison of cloud ice content predictions - vertically integrated (top), UTLS (bottom): E5M1 standard calculations (left), E5M1EQSAM3 based on AW and PM with explicit freezing point depression (right). Model similar to Fig. 5.

To investigate to what extent the cloud ice content can be calculated directly, Fig. 6 presents an additional snap shot for 3 June 2004 (12:00 GMT), comparing the E5M1 base model (left two panels) with that including EQSAM3 for the entire troposphere (top panels) and the UTLS region (bottom panels). The calculations including EQSAM3 assume that the excess aerosol water with respect to the limit based on the saturation water mass represents the condensed cloud water mass. In addition, the freezing point depression associated with salt solutes was taken into account and computed from the total number of moles of solute in solution and the cryoscopic constant of water, which is $1.86\left[\mathrm{~K} \mathrm{~mol}^{-1}\right]$.

Figure 6 (right panels) shows that the ice content and distribution predicted by EQSAM3 compares qualitatively, though remarkably well with the original E5M1 parameterized ice clouds, in particularly for the UTLS region. Contrasting the explicit treatment of freezing point depression with a simpler constraint, i.e. a constant freezing point tem- perature $(T=243[\mathrm{~K}])$, for the same aerosol load shows much poorer agreement, which is most noticeable for the UTLS (not shown). This comparison - though not rigorous - indicates that:

1. The explicit prediction of aerosol water mass enables the direct calculation of large scale (i.e. model grid scale) cloud properties.

2. Cloud properties are sensitive to aerosol chemistry; the latter determines the particle hygroscopic growth and water uptake, which in turn controls the ambient size distributions of aerosols and cloud droplets at their initial formation.

To consistently apply these concepts in regional and global cloud modeling studies it will be necessary to fully couple EQSAM3 with other cloud processes such as the collision and coalescence of droplets and precipitation formation. 


\section{Summary and discussion}

\subsection{From laboratory to atmosphere}

Under controlled laboratory conditions, the water mass is fixed so that solution properties such as the solute molarity or molality can be measured, upon which non-ideal solution properties such as activity coefficients can be defined. Application to the atmosphere requires the transformation of these solution properties, i.e. they need to be a function of RH.

In the atmosphere aerosol and cloud water both depend on the water vapor mass. In turn, the water vapor mass is to a large extent controlled by the ambient temperature $(T)$, which determines both the amount of water vapor available through evaporation and the maximum amount of water vapor that the air can contain at $T$. At $\mathrm{RH} \geq 1$ excess water vapor directly condenses to the aqueous or ice phase, while at $\mathrm{RH}<1$ only a fraction of the saturation water mass is in equilibrium with the aqueous phase. At subsaturation the maximum amount of aerosol water is limited only by the available water vapor mass, and at saturation or supersaturation by the $T$-dependent maximum water vapor mass. Under all conditions for which thermodynamic equilibrium can be assumed, the condensed water mass is proportional to the mass of solute(s), since the RH determines the water activity of the solution that must hence remain constant.

Although dynamic processes such as cloud formation imply non-equilibrium conditions, quasi-equilibrium might be assumed for grid-scale processes, being a reasonable approximation for most regional and large scale modeling applications. The reason is that the condensation of water vapor on aerosol or cloud droplets is a relatively fast process (order of seconds) compared to the modeling time steps that are usually much longer (order of minutes or more).

\subsection{Conceptual difficulty}

The "classical" equilibrium thermodynamics (e.g. Denbigh, 1981; Seinfeld and Pandis, 1998; Wexler and Potukuchi, 1998) does not explicitly account for the amount of water involved by hydration and the dissociation of e.g. salt solutes, although hydration drives the hygroscopic growth of natural and man-made aerosols. Water is only considered when explicitly consumed or produced. In addition, the water mass used to define e.g. aerosol activity coefficients is kept constant, which is reasonable for laboratory but not for atmospheric conditions.

We overcome these limitation by reformulating equilibrium thermodynamics and hygroscopic growth of atmospheric aerosols into fog, haze and clouds by consistently accounting for the water associated with the hydration of solutes, and by constraining the condensed water by either the available water vapor mass or the saturation limit. The underlying physical principles that govern hydration have been generalized based on first principles that explain osmosis.

\subsection{Osmosis}

Following Arrhenius' theory of partial dissociation and the original description of osmosis by van't Hoff and Ostwald, we extended van't Hoff's gas-solution analogy to non-ideal solutions by introducing (a) a stoichiometric coefficient for water $\left(v_{w}=v_{w}^{+}+v_{w}^{-}\right)$to account for the actual number of moles of water causing hydration, and (b) an associated effective coefficient for the solute $\left(v_{e}=v_{e}^{+}+v_{e}^{-}\right)$to account for the effective number of moles arising from partial or complete solute dissociation.

The advantage of using these stoichiometric coefficients is that they allow to analytically solve the gas/liquid/solid equilibrium partitioning and associated water uptake. This considerably simplifies the numerical solution and limits CPU time. Note that activity coefficients applied in standard methods vary with the concentration range, which depends on both the solute concentration and on aerosol water, which in turn is used to determine the solute concentration. These dependencies require an CPU demanding iterative numerical solution. Moreover, their use is restricted to compounds for which comprehensive thermodynamic data are available.

In contrast, $v_{w}$ and $v_{e}$ can be easily determined for any compound from its solubility, and used to analytically solve the gas-aerosol partitioning of mixtures, because these coefficients can be assumed constant over the entire activity range. For a further discussion about the state of dissociation of electrolytes in solutions we refer the interested reader to Heyrovska (1989).

\subsection{Solubility}

Common with Heyrovska (1989), we use solute specific coefficients to calculate the vapor pressure reduction over a wide concentration range. In contrast to Heyrovska (1989), who did not explicitly account for the water mass consumed by hydration, we additionally use a stoichiometric constant for water $v_{w}$, which can be derived from the solute solubility according to Eq. (19). The advantage is that only one - easily measured and commonly used - solubility value is needed. The disadvantage is that for salt solutes that do not dissociate completely the effective dissociation constant $v_{e}$ must be known. However, $v_{e}$ can be determined with $v_{w}$ by Eq. (20) if compared to water activity measurements.

\subsection{Water activity}

Although the discussion of water activity is intricate, being relevant to many areas including for instance pharmaceutical and food industry (see e.g. the web portal by M. Chaplin http://www.lsbu.ac.uk/water/activity.html), atmospheric applications allow for simplifications, as shown in this work. One reason is that at equilibrium the osmotic pressure, if expressed in terms of water, e.g. associated with the hydration of a salt solute, equals the partial vapor pressure of water, 
so that the water activity remains constant and equal to $\mathrm{RH}$ (Sect. 2). One important consequence is that the amount of water required for hydration is directly proportional to the amount of solute.

\subsection{Kelvin-term}

Another consequence, not addressed thus far, is that the vapor pressure reduction associated with dissolution, hydration and dissociation of a solute equals the osmotic pressure difference, independently of the surface curvature (see Fig. 1). At equilibrium the osmotic pressure of the solute or solvent (in solution) equals the corresponding partial vapor pressures of solute or solvent above the solution. In contrast to the theoretical solvent partial pressure in solution, the (measurable) osmotic pressure is an effective pressure and hence implicitly accounts for surface tension and non-ideality effects. Note that Raoult's law describes this for the solvent and Henry's law for the solute, and both can be generalized to account for solution non-idealities by including either activity coefficients or the stoichiometric coefficients $v_{w}$ and $v_{e}$. Note that e.g. surface tension or droplet curvature affects the solubility and at equilibrium is implicitly accounted for by $v_{w}$.

The advantage of our method is that the water uptake of atmospheric aerosols can be directly calculated for any particle size from the solute solubility (if known). The so called "Kelvin-term" that accounts for the curvature of nanometer sized particles is not needed in case of equilibrium. Such small particles are rarely in equilibrium with the ambient air; rather they grow relatively fast due to hygroscopic growth, whereby their equilibrium size is maintained by RH. Thus, except for the calculation of nucleation grow rates (nonequilibrium conditions) surface curvature corrections are not required.

\subsection{Köhler-equation}

Another consequence is that in equilibrium the widely used Köhler-equation becomes redundant, since the Kelvin-term is not required for the calculation of the aerosol particle size if aerosol water is consistently treated. In fact, the use of the Köhler-equation is somewhat misleading, since most approximations of the $1 / r-1 / r^{3}$ - radius dependency of the "surface-(Kelvin)" and "volume (Raoult)" term in the Köhler equation are inaccurate. Usually, neither concentration changes in the surface tension are accounted for nor is the fact that the volume of water is not constant but dependent on relative humidity.

By explicitly including aerosol water the $1 / r-1 / r^{3}$ radius dependency is automatically accounted for. Note that $r$ is usually approximated as the ambient radius (e.g. Pruppacher and Klett, 1997), while the more explicit formulation (see e.g. Dufour and Defay, 1963) actually yields a difference between the ambient (wet) radius and the dry radius of the solute, expressing the radius of the aerosol water which, however, cancels out if the volume occupied by water is not assumed to be constant.

\subsection{Cloud condensation nuclei}

Nevertheless, the Köhler-equation has been successfully used in many applications to calculate the activation of aerosol particles as cloud condensation nuclei (CCN) and to describe cloud droplet size spectra. Is this really needed, since the definition of $\mathrm{CCN}$ requires that a specific though arbitrary supersaturation is prescribed? As illustrated in Sect. 4.3, aerosol particles can grow by water uptake into cloud droplets simply by allowing ambient conditions to include $\mathrm{RH} \geq 1$. Obviously, the growing particles compete for the available water vapor, and the likelihood for larger droplets to collect the available water vapor is highest, so that they grow at the expense of smaller ones. Hence, at equilibrium a bimodal size distribution establishes, as observed, with larger droplets and smaller ones that have collected more and less water vapor, respectively. The larger ones can settle gravitationally dependent on their mass and local vertical air velocities, and by collision and coalescence they can ultimately grow into rain drops. The equilibrium droplet size distribution to a large extent depends on the cloud dynamics, whereas the initial size is determined by the aerosol water mass. Therefore, our method eliminates the need to define $\mathrm{CCN}$. It furthermore allows to directly relate the chemical properties of aerosol particles to cloud droplets, being a requirement to explicitly link emission sources of atmospheric trace constituents in models to the physical properties of aerosol particles, fog, haze and clouds.

\subsection{Final comments}

Our new concept developed in Sect. 2 uses the fundamental equations and ideas proposed more than a century ago to explain the principles of osmosis. Our contribution is that we have applied and transformed these ideas by consistently accounting for water involved in the hydration of salt or nonelectrolyte solutes by the introduction of the stoichiometric constants $v_{w}$ and $v_{e}$. This yields both a) a more general formulation of the principles that govern osmosis that now extends to non-ideal solutions, and b) a consistent calculation of the hygroscopic growth of atmospheric aerosols.

\subsubsection{Mixed solutions}

It is worth mentioning that the use of $v_{w}, v_{e}$ is not only limited to the calculation of single solute solution molalities or dilute solutions. As demonstrated by the application of EQSAM3 to observations of sea salt, desert dust and pollution particles over the Mediterranean Sea, $v_{w}, v_{e}$ can also be assumed constant for highly concentrated mixed solutions (see Fig. 3). 


\subsubsection{Gibbs free energy}

The consistent use of $v_{w}, v_{e}$ also eliminates the need to iteratively minimize the Gibbs free energy in model applications, since at equilibrium the total Gibbs free energy change must be zero when water is included in the summation. As a consequence, the gas/liquid/solid partitioning can be solved analytically, which saves a considerable amount of CPU-time (see also Metzger et al., 2002) so that applications in complex regional or global models become feasible.

\subsubsection{Equilibrium constants}

The consistent use of $v_{w}, v_{e}$ furthermore substitutes the use of equilibrium constants, since the Gibbs free energy is zero and $v_{w}$ implicitly includes the relevant information to compute the equilibrium phase partitioning as it is derived from the solute solubility. The successful application of EQSAM3 demonstrates that this approach suffices (Fig. 3). Note that EQSAM3 merely uses solubilities as measured for each solute in Table 1.

\subsubsection{Relative humidity of deliquescence}

The use of solubility measurements together with $v_{w}, v_{e}$ yields the relative humidity of deliquescence (RHD), which corresponds to the $\mathrm{RH}$ at which the solution is saturated with respect to a solute. Any increase of the solute then results in its precipitation, whereby the solid is in equilibrium with its ions in the aqueous phase. If Eq. (21) is used, complex computations are redundant. Even efflorescence and deliquescence RHDs of single or mixed salt solutions can be calculated from Eq. (21) (see Sect. 4.1 point 5 and 9). Note that all these values provide independent evidence of the accuracy of Eq. (20) and the applicability of $v_{w}, v_{e}$ to concentrated mixed solutions. Previous approaches were dependent on activity coefficients.

\subsubsection{Activity coefficients}

With the successful application of EQSAM3 we further demonstrate that activity coefficients are only required for (semi-) volatile compounds, and that they can be directly calculated from RH when $v_{w}, v_{e}$ are known, i.e. by substituting Eq. (20) into Eq. (14), and considering Eqs. (15) and (16) (Sect. 4.1). Note that (semi-) volatile compounds can be additionally driven out of the aqueous phase into the gas phase in contrast to non-volatile compounds, which can only precipitate into the solid phase when the $\mathrm{RH}$ drops and the water activity decreases. The gas/liquid partitioning is thus determined by the solute solubility if $v_{w}, v_{e}$ are used to calculate the aerosol water mass, since at equilibrium a solution is always saturated and because the RH determines the water activity, whereby $\mathrm{RH}<1$ is already a correction for solution non-ideality.
For instance, the mean molal binary activity coefficient of ammonium nitrate used in EQSAM3 compares well with that of ISORROPIA, also for concentrated mixed solutions (Fig. 3). Even very sensitive aerosol properties such as the solution $\mathrm{pH}$ compare well, and low aerosol nitrate concentrations can be effectively predicted. Although very low aerosol nitrate concentrations could not be predicted with EQSAM2 (mainly since the use of the ammonium nitrate equilibrium constant is insufficient for certain mixed aerosol systems) the mean binary activity coefficient of ammonium nitrate is comparable in both versions.

Note that EQSAM2 used activity coefficients that have been derived according to the method described in Metzger et al. (2002). Zaveri et al. (2005) compared this method with various other and well established activity coefficient calculation methods and recognized that this was the first time to express binary mean activity coefficients of individual electrolytes directly as a function of water activity. Unfortunately, Zaveri et al. (2005) have overlooked that the method of Metzger et al. (2002) is not limited to dilute binary systems but also extends to multicomponent activity coefficients of concentrated mixed solutions, as demonstrated in Fig. 3. The reason is that Zaveri et al. (2005) applied these methods to laboratory conditions, where activity coefficients are measured as function of solute concentration but not of the equilibrium aerosol water mass, being itself a function of $\mathrm{RH}$ in the atmosphere - thus, a conceptual difficulty we hope to have eliminated with our present work.

\subsubsection{Equilibrium assumption}

The equilibrium assumption is an essential and central element in physical chemistry. For instance, Henry's Law constant describes the partitioning of a gas between the atmosphere and the aqueous phase. It can be based on direct measurements or calculated as the ratio of the pure compound vapor pressure to the solubility. The latter approximation is reliable only for compounds of very low solubility. In fact, values of Henry's law constant found in the literature frequently differ substantially. Despite that Henry's law constants are determined on the basis of equilibrium, they are used to solve chemical systems which are not in equilibrium.

Similarly, our formulas can be applied to non-equilibrium conditions by solving the chemical system dynamically. The accuracy achievable with our equations, e.g. Eqs. (20), (21) or (23), merely depends on the accuracy and applicability of the solubility measurements from which the solute specific constants $v_{w}, v_{e}$ have been derived. Note that this also includes the temperature dependency. The approximation used in EQSAM3 might not necessarily suffice for all compounds, and explicit temperature dependencies can be easily invoked to derive the solute specific constants $v_{w}$ and $v_{e}$. The assumption that droplet growth on aerosol particles can be approximated by an equilibrium approach can be conceptually tested by observing the steady state conditions of e.g. stratocumulus 
and cumulus clouds. Even though droplets continually grow and evaporate by local moisture variations, the cloud appearance (i.e. the mean cloud properties) varies little unless the overall dynamical or thermodynamical boundary conditions change.

\subsubsection{Importance of aerosol water}

The applicability of $v_{w}, v_{e}$ to mixed solutions, as determined from single solubility measurements, is particularly useful for atmospheric applications, since complete knowledge of the actual solute composition is often not available. Especially the efflorescence and deliquescence relative humidities of single solute and mixed solutions, which can be calculated from $v_{w}, v_{e}$ by Eq. (21), are crucial as they determine at which RH ambient aerosol particles grow due to water uptake into the size range of efficient solar radiation scattering and subsequently of cloud formation.

Aerosol water is hence central in modeling atmospheric chemistry, visibility, weather and climate. It is determined by the hygroscopicity of natural and man-made aerosols, whereby the hygroscopicity can be altered by air pollution. Aerosol water can thus provide a direct link between air pollution, weather and climate.

\subsubsection{Limitation}

Our new method is based on thermodynamic equilibrium and hence does not directly apply to non-equilibrium conditions that can occur in the atmosphere. However, for most modeling applications thermodynamic equilibrium suffices, since equilibrium involving water is usually established in seconds, while model time-steps usually exceed a few minutes.

For instance, our method allows to predict the RHD of pure salt compounds, which are required to calculate the partitioning between the solid and liquid phase, and hence the $\mathrm{RH}$ and $T$ at which a salt takes up water from the atmosphere. The equilibrium assumption implies that a solution is saturated if the RH equals the RHD; if the RH drops the solution becomes supersaturated which causes solute precipitation until the solution is saturated again (so that the saturation molality remains constant). Although most salts deliquesce nearly immediately, certain salt mixtures as found in the polluted atmosphere might alter or even suppress the deliquescence behavior of natural aerosols, so that the compounds deliquesces over a different RH range. In this case the equilibrium assumption can break down. However, the RHD calculations with Eq. (21) might still be valid if the actual molality of such an aerosol mixture is used along the $\mathrm{RH}$ trajectory, or in case it is approximated by using effective solubilities. Therefore, even the drying process of aerosols can be modeled according to Sect. 4.1 (point 5, 8, 9), where the aerosols follow the upper tail of the so-called hysteresis loop; the lower tail is described by the wetting process and deliquescence.
Nevertheless, the water uptake is mainly determined by salt compounds for which the equilibrium assumption and the derived additivity of the osmotic partial pressures is valid. Note that the pressure additivity is a consequence of the gassolution analogy and implies molar volume additivity, but that the additivity might not always be a good assumption. For instance non-salt solutes and compounds whose molecular structure either collapses due to hydration, or capillar effects arising from the particles morphology or particle coagulation, might temporarily lead to non-equilibrium conditions and hence to a failure in the assumption of additivity (P. Winkler, personal communication). This would hence affect the summation of the partial aerosol water masses and the RHD of the mixed aerosol phase, since in our method $v_{e}$ and $v_{w}$ are summarized in this case.

However, such compounds contribute usually only little to the overall water uptake, so that the aerosol water mass of ambient aerosols might still be approximated sufficiently accurately. Similarly, our method may be used to model the initial cloud conditions by assuming quasi-equilibrium, since the water uptake is limited by the actually available water vapor mass as determined by atmospheric dynamics and transport.

\section{Conclusions}

Based on first thermodynamics principles we conceptually applied osmotic pressure to aerosols, fogs, hazes and clouds. When transformed from laboratory to atmospheric conditions, as summarized by Eqs. (6)-(10), it follows that the water needed for hydration is proportional to the amount of solute and governed by the type of solute and RH. To account for the moles of water needed for hydration and dissociation we introduced the solute specific effective dissociation coefficient $v_{e}$ and the coefficient for water, $v_{w}$. Both coefficients are independent of the solute concentration, and can directly be computed from the solute solubility of weak and strong electrolytes (organic and inorganic salts), or non-electrolytes (e.g. sugars, alcohols, or dissolved gases).

We demonstrated the applicability of this concept in a new thermodynamic equilibrium model (EQSAM3) for mixed solutions. The results of EQSAM3 compare well to field measurements and other thermodynamic equilibrium models (EQMs) such as ISORROPIA and SCAPE2. The latter two models use comprehensive (and CPU demanding) algorithms to solve the "classical" aerosol thermodynamics (being rather complex for mixed solutions), whereas EQSAM3 solves the gas/liquid/solid partitioning and hygroscopic growth analytically and non-iteratively. EQSAM3 computes various aerosol properties that are difficult to measure such as sizesegregated particle composition, efflorescence and deliquescence relative humidities of singe or mixed solutions, solution $\mathrm{pH}$, by accounting for major inorganic and organic com- 
pounds (Table 1 lists nearly 100, and the list can be easily extended).

The advantage of our new model is that it requires only the compound solubility to derive all further thermodynamic data, whereby the solubility is commonly used, easily measured, and available for many inorganic and organic compounds (e.g. from CRC Handbook of Chemistry and Physics, 2006). Previous EQMs rely on various complex laboratory measurements (e.g. water activities, activity coefficients, or RHDs), which are not only limited to certain compounds but also involve numerically complex and hence expensive computations. Instead the computational efficiency of EQSAM3 allows application in regional and global atmospheric-chemistry and climate models.

We further illustrated that the water uptake of aerosols is directly proportional to the soluble aerosol load, whereby the hygroscopic growth depends on the type of solute. We presented calculations of water uptake as a function of RH for selected inorganic salt solutions; the electronic supplement extends this to all compounds shown in Table 1. An application of EQSAM3 to mixed inorganic and organic salt solutions is included and indicates the importance of aerosol chemistry for visibility predictions.

Our outlook for future applications of EQSAM3 also involved global chemistry-transport and meteorological modeling, including aerosol-cloud interactions. The EQSAM3 computation of aerosol water - without assumptions about the activation of aerosol particles - holds promise for the explicit computation of large scale fogs, hazes and clouds, including cloud cover, the initial cloud water and cloud ice. When aerosol water is explicitly accounted for, aerosol and cloud thermodynamics can be easily coupled and hence substantially simplified.

Our new approach will enable model calculations that directly relate various natural and anthropogenic emissions of trace gases and aerosols to fog, haze and cloud formation, so that air pollution effects on weather and climate can be studied explicitly.

\section{Appendix A List of acronyms, symbols and indices}

The following tables list all acronyms, symbols and indices used throughout the paper. Names of chemical substances are listed in the electronic supplement (http://www.atmos-chem-phys.net/7/3163/2007/ acp-7-3163-2007-supplement.zip).

Table A1. List of acronyms and abbreviations.

\begin{tabular}{ll}
\hline Abbreviation & Name \\
\hline AS & Ammonium Sulfate \\
CCN & Cloud Condensation Nuclei \\
ECHAM5 & Climate Model (Röckner et al., 2003) \\
EPA & Environmental Protection Agency (USA) \\
EQM & Thermodynamic EQuilibrium Model \\
EQSAM3 & EQuilibrium Simplified Aerosol Model, version 3 \\
& EQM (this work) \\
E5M1 & ECHAM5/MESSy (Jöckel et al., 2006) \\
F2/C2 & Fine/Coarse Chemical System (Metzger et al., 2006) \\
GEOS & Geostationary Satellite \\
IPCC & Intergovernmental Panel on Climate Change \\
ISORROPIA & EQM (Nenes et al., 1998) \\
LMW & Low Molecular Weight \\
MINOS & Mediterranean INtensive Oxidant Study \\
& (Lelieveld et al., 2002) \\
MESSy & Modular Earth Submodel System \\
MOHp & Meteorological Observatory Hohenpeißenberg \\
PM & Particulate Matter \\
ppb & Parts per Billion by volume \\
SCAPE2 & EQM (Meng et al., 1995) \\
T63 & Climate Model Resolution ( 1.9 degree) \\
UTLS & Upper Troposphere - Lower Stratosphere \\
\hline
\end{tabular}

Table A2. List of units.

\begin{tabular}{lll}
\hline Symbol & Name & Unit \\
\hline $\mathrm{Pa}$ & SI-Unit Pascal & $\mathrm{N} / \mathrm{m}^{2}$ \\
$\mathrm{~N}$ & SI-Unit Newton & $\mathrm{kg} \mathrm{m} / \mathrm{s}^{2}$ \\
$\mathrm{~J}$ & SI-Unit Joule & $\mathrm{Pa} \mathrm{m}=\mathrm{N} / \mathrm{m}^{2} \mathrm{~m}^{3}=\mathrm{Nm}$ \\
\hline$R$ & universal gas constant & $8.314 \mathrm{~J} / \mathrm{mol} / \mathrm{K}$ \\
\hline
\end{tabular}

Table A3. List of indices.

\begin{tabular}{ll}
\hline Abbreviation & Name \\
\hline$(\mathrm{cr})$ & crystalline \\
$(\mathrm{aq})$ & aqueous \\
$(\mathrm{g})$ & gaseous \\
$(+)$ & superscript for "cation" \\
$(-)$ & superscript for "anion" \\
$( \pm)$ & superscript for "ion pair" \\
$w$ & subscript for "water" \\
$s$ & subscript for "solute" \\
$e$ & subscript for "effective" \\
$i$ & subscript for " $i$ th- of $k$-components" \\
$j$ & subscript for " $j$ th-compound or chemical reaction" \\
$k$ & subscript for "the total number of components" \\
\hline
\end{tabular}


Table A4. List of symbols.

\begin{tabular}{|c|c|c|}
\hline Symbol & Name & Unit \\
\hline & Stoichiometric coefficient: & \\
\hline$v_{w}$ & solvent (water) & - \\
\hline$v_{w}^{+}$ & water cation $\left(\mathrm{H}_{3} \mathrm{O}^{+}\right)$ & - \\
\hline$v_{w}^{-}$ & water anion $\left(\mathrm{OH}^{-}\right)$ & - \\
\hline$v_{s}$ & solute (for complete dissociation) & - \\
\hline$v_{e}$ & solute (for effective dissociation) & - \\
\hline$v_{s}^{+}$ & solute cation (complete dissociation) & - \\
\hline$v_{e}^{+}$ & solute cation (effective dissociation) & - \\
\hline$v_{s}^{-}$ & solute anion (complete dissociation) & - \\
\hline$v_{e}^{-}$ & solute anion (effective dissociation) & - \\
\hline \multirow[t]{2}{*}{$v_{i, j}$} & of $i$ th-component of $j$ th-chem. reaction & - \\
\hline & total number of moles: & \\
\hline$n^{(g)}$ & in the gas phase & mol \\
\hline$n$ & in the aqueous phase & mol \\
\hline$n_{s}^{(\mathrm{g})}$ & of solute (gas phase) & mol \\
\hline$n_{s}^{(\mathrm{cr})}$ & of solute (crystalline phase) & mol \\
\hline$n_{s}$ & of solute (aqueous phase) & mol \\
\hline$n_{w}^{(\mathrm{g})}$ & of water (gas phase) & mol \\
\hline$n_{w}$ & of water (aqueous phase) & mol \\
\hline$\tilde{n}_{w}$ & of solute-mass equivalent in terms of water & mol \\
\hline$n_{w, o}^{(\mathrm{g})}$ & of water (gas phase) at ref. conditions & mol \\
\hline$n_{w, o}$ & of water (aqueous phase) at ref. conditions & mol \\
\hline$n_{s, o}$ & of solute (aqueous phase) at ref. conditions & mol \\
\hline$z_{s,+, j}$ & of electrons transferred by $1 \mathrm{~mol}$ of cation & - \\
\hline$z_{s,-, j}$ & of electrons transferred by $1 \mathrm{~mol}$ of anion & - \\
\hline$z_{s, j}^{ \pm}$ & of electrons transferred by $1 \mathrm{~mol}$ of ion-pair & - \\
\hline$k_{ \pm}$ & $\begin{array}{l}\text { of water consumed by dissociation } \\
\text { into } 1 \mathrm{~mol} \text { of cation/anion }\end{array}$ & - \\
\hline$N_{ \pm}$ & of water consumed by molar dissociation & - \\
\hline$m_{s+}$ & cation solute molality & $\mathrm{mol} / \mathrm{kg}$ \\
\hline$m_{s-}$ & anion solute molality & $\mathrm{mol} / \mathrm{kg}$ \\
\hline$m_{s}$ & solute molality & $\mathrm{mol} / \mathrm{kg}$ \\
\hline$m_{s s}$ & single solute molality & $\mathrm{mol} / \mathrm{kg}$ \\
\hline$m_{s s, \text { sat }}$ & single solute molality at saturation & $\mathrm{mol} / \mathrm{kg}$ \\
\hline$\gamma_{s+}$ & cation (molal) activity coeff. of solute (s) & $\mathrm{kg} / \mathrm{mol}$ \\
\hline$\gamma_{s-}$ & anion (molal) activity coeff. of solute (s) & $\mathrm{kg} / \mathrm{mol}$ \\
\hline$\gamma_{s}^{ \pm}$ & mean (molal) ion-pair activity coefficient & $\mathrm{kg} / \mathrm{mol}$ \\
\hline$\gamma_{s(\text { molal }), j}^{ \pm}$ & mean (molal) binary activity coeff. & $\mathrm{kg} / \mathrm{mol}$ \\
\hline$\gamma_{s(\mathrm{molar}), j}^{ \pm}$ & mean (molar) binary activity coeff. & $1 / \mathrm{mol}$ \\
\hline$\xi_{s, j}$ & relative charge density of the solution & - \\
\hline$a_{s+}$ & cation solute activity (aqueous phase) & $0-1$ \\
\hline$a_{s-}$ & anion solute activity (aqueous phase) & $0-1$ \\
\hline$a_{s}$ & solute activity (aqueous phase) & $0-1$ \\
\hline$a_{s, o}$ & $\begin{array}{l}\text { solute activity (aqueous phase) } \\
\text { at reference conditions }\end{array}$ & $0-1$ \\
\hline$a_{w+}$ & water cation $\left(\mathrm{H}_{3} \mathrm{O}^{+}\right)$activity (aq. phase) & $0-1$ \\
\hline$a_{w-}$ & water anion $\left(\mathrm{OH}^{-}\right)$activity (aq. phase) & $0-1$ \\
\hline$a_{w}$ & water activity (aqueous phase) & $0-1$ \\
\hline$a_{w, o}$ & $\begin{array}{l}\text { water activity (aqueous phase) } \\
\text { at reference conditions }\end{array}$ & $0-1$ \\
\hline$g_{s}^{o}$ & $\begin{array}{l}\text { (partial) Gibb's free energy of solute (s) } \\
\text { at reference conditions }\end{array}$ & $\mathrm{kJ}$ \\
\hline$g_{w}^{o}$ & $\begin{array}{l}\text { (partial) Gibb's free energy of solvent (water) } \\
\text { at reference conditions }\end{array}$ & $\mathrm{kJ}$ \\
\hline$g_{i, j}^{o}$ & $\begin{array}{l}\text { (partial) Gibb's free energy of } i \text { th-component } \\
\text { of } j \text { th-chemical reaction at ref. conditions }\end{array}$ & $\mathrm{kJ}$ \\
\hline
\end{tabular}

Table A4. List of symbols (continued).

\begin{tabular}{|c|c|c|}
\hline Symbol & Name & Unit \\
\hline$\Delta$ & total change in: & \\
\hline$\Delta E$ & total energy & $\mathrm{kJ}$ \\
\hline$\Delta G$ & Gibb's free energy & $\mathrm{kJ}$ \\
\hline$\Delta V^{(\mathrm{aq})}$ & volume (aqueous phase) & $\mathrm{m}^{3}$ \\
\hline$\Delta n_{s}$ & (total) moles of solute & mol \\
\hline$\Delta n_{w}$ & (total) moles of water & mol \\
\hline$\Delta P_{w}^{(g)}$ & (partial) water vapor pressure (gas phase) & $\mathrm{Pa}$ \\
\hline$\Delta \Pi_{w}$ & (partial) osmotic pressure of solvent (water) & $\mathrm{Pa}$ \\
\hline$\Delta \Pi_{s}$ & (partial) osmotic pressure of solute (s) & $\mathrm{Pa}$ \\
\hline$\Delta \Pi$ & (total) osmotic pressure (aqueous phase) & $\mathrm{Pa}$ \\
\hline$\Delta \mathrm{RH}$ & (fractional) relative humidity & $0-1$ \\
\hline$\Delta a_{w}$ & (fractional) water activity (aqueous phase) & $0-1$ \\
\hline & (partial) vapor pressure of: & \\
\hline$P_{w}^{(\mathrm{aq})}$ & water (aqueous phase) & $\mathrm{Pa}$ \\
\hline$P_{w}^{(\mathrm{g})}$ & water (gas phase) & $\mathrm{Pa}$ \\
\hline$P_{w, s a t}^{(\mathrm{g})}$ & water at saturation (gas phase) & $\mathrm{Pa}$ \\
\hline$P_{w, o}^{(\mathrm{g})}$ & water (gas phase) at reference conditions & $\mathrm{Pa}$ \\
\hline$\Pi_{s}$ & $\begin{array}{l}\text { (partial) osmotic pressure (aqueous phase) of: } \\
\text { solute (s) }\end{array}$ & $\mathrm{Pa}$ \\
\hline$\Pi_{w}$ & solvent (water) & $\mathrm{Pa}$ \\
\hline$\Pi_{s, o}$ & solute (s) at reference conditions & $\mathrm{Pa}$ \\
\hline$\Pi_{w, o}$ & solvent (water) at reference conditions & $\mathrm{Pa}$ \\
\hline$P$ & (total) atmospheric pressure (gas phase) & $\mathrm{Pa}$ \\
\hline$\Pi$ & (total) osmotic pressure (aqueous phase) & $\mathrm{Pa}$ \\
\hline$\Pi_{o}$ & $\begin{array}{l}\text { (total) osmotic pressure of pure solvent (water) } \\
\text { at reference conditions }\end{array}$ & $\mathrm{Pa}$ \\
\hline$\chi_{w}$ & mole fraction of water & $0-1$ \\
\hline$\chi_{\sim} \chi_{s}$ & mole fraction of solute & $0-1$ \\
\hline$\tilde{\chi}_{w}$ & generalized mole fraction of water & $0-1$ \\
\hline$\tilde{\chi}_{s}$ & generalized mole fraction of solute & $0-1$ \\
\hline$\rho_{s}$ & solute density & $\mathrm{g} / \mathrm{cm}^{3}$ \\
\hline$\rho_{w}$ & water density & $\mathrm{g} / \mathrm{cm}^{3}$ \\
\hline$w_{s}$ & solute mass fraction & $0-1$ \\
\hline$W_{s}$ & solute mass fraction & $\%$ \\
\hline$m_{s}$ & mass of solute & g \\
\hline$m_{w}$ & mass of water & g \\
\hline$M_{S}$ & Molar mass of solute & $\mathrm{g} / \mathrm{mol}$ \\
\hline$M_{w}$ & Molar mass of water & $\mathrm{g} / \mathrm{mol}$ \\
\hline K & molal equilibrium constant of reaction $(\mathrm{R})$ & - \\
\hline$K_{s p}$ & solubility product constant & $(\mathrm{mol} / \mathrm{kg})^{v_{s}}$ \\
\hline$V^{(\mathrm{g})}$ & total volume (gas phase) & $\mathrm{m}^{3}$ \\
\hline$V^{(\mathrm{aq})}$ & total volume (aqueous phase) & $\mathrm{m}^{3}$ \\
\hline$r$ & radius & $\mathrm{m}$ \\
\hline PM & total number of moles (liquid and solid phase) & $\mathrm{mol} / \mathrm{m}^{3}$ (air) \\
\hline PMt & total particulate mass (liquid and solid phase) & $\mu \mathrm{g} / \mathrm{m}^{3}$ (air) \\
\hline PMs & total particulate mass (solid phase) & $\mu \mathrm{g} / \mathrm{m}^{3}$ (air) \\
\hline $\mathrm{pH}$ & acid-base indicator (potentia Hydrogenia) & \\
\hline RH & fractional relative humidity & $0-1$ \\
\hline RHD & relative humidity of deliquescence & $0-1$ \\
\hline$T$ & temperature & $\mathrm{K}$ \\
\hline$T_{o}$ & $\begin{array}{l}\text { temperature } \\
\text { at reference conditions }\end{array}$ & K \\
\hline$Z$ & ionic strength of the solution & $\mathrm{mol} / \mathrm{kg}\left(\mathrm{H}_{2} \mathrm{O}\right)$ \\
\hline$Z_{s,+}$ & total molar cation charge & - \\
\hline$Z_{s,-}$ & total molar anion charge & - \\
\hline
\end{tabular}


Acknowledgements. This work was financed through the project ANTISTORM (Anthropogenic Aerosols Triggering and Invigorating Severe Storms http://antistorm.isac.cnr.it/index.html) through the European Community program NEST-12444 (New and emerging science and technology, http://www.cordis.lu/nest/).

We acknowledge the German weather service for providing the MOHp measurements and the colleagues at the Max Planck Institute for Meteorology for providing the climate model ECHAM5. We are grateful to the MESSy development group of the Max Planck Institute for Chemistry for providing E5M1. We further thank N. Mihalopoulos and the MINOS measurement group for the gas/aerosol measurements.

Edited by: M. Dameris

\section{References}

Arrhenius, S.: Z. Phys. Chem., 1, 631, 1887.

Chan, C. K., Flagan, R. C., and Seinfeld, J. H., Water activities of $\mathrm{NH}_{4} \mathrm{NO}_{3} /\left(\mathrm{NH}_{4}\right)_{2} \mathrm{SO}_{4}$ solutions, Atmos. Environ., 26A, 1661$1673,1992$.

Cohen, M. D., Flagan, R. C., and Seinfeld, J. H. Studies of concentrated electrolyte solutions using the electrodynamic balance. 1 . Water activities for single electrolyte solutions, J. Phys. Chem., 91, 4563-4574, 1987a.

Cohen, M. D., Flagan, R. C., and Seinfeld, J. H. Studies of concentrated electrolyte solutions using the electrodynamic balance. 2 . Water activities for mixed electrolyte solutions, J. Phys. Chem., 91, 4575-4582, 1987b.

Chemical Rubber Company (CRC): Handbook of Chemistry and Physics, 86th Edition, Taylor and Francis Group LLC, 20042005, CD-ROM version 2006.

Clegg, S. L., Milioto, S., and Palmer, D. A.: Osmotic and Activity Coefficients of Aqueous (NH4)2SO4 as a Function of Temperature, and Aqueous (NH4)2SO4-H2SO4 Mixtures at 298.15 K and 323.15 K J. Chem. Eng. Data, 41, 3, 455-467, 1996.

Clegg, S. L. and Seinfeld, J. H.: Thermodynamic Models of Aqueous Solutions Containing Inorganic Electrolytes and Dicarboxylic Acids at 298.15 K. 2. Systems Including Dissociation Equilibria, J. Phys. Chem. A, 110, 17, 5718-5734, 2006.

Clegg, S. L., Brimblecombe, P., and Wexler, A. S.: Thermodynamic Model of the System H+-NH4+-Na+-SO42-NO3-Cl-H2O at 298.15 K J. Phys. Chem. A, 102, 12, 2155-2171, 1998.

Denbigh, K.: The Principles of Chemical Equilibrium, 4th ed., Cambridge Univ. Press, New York, 1981.

Dufour, L. and Defay, R.: Thermodynamics of Clouds, Academic Press, New York, 1963, 1427-1434, 1998.

Environmental Protection Agency (EPA): Air quality criteria for particulate matter, EPA/600/P-95/001cF, 1996.

Gibbs, J. W.: On the equilibrium of heterogeneous substances (1876), in: Collected Works, Vol. 1, Longmans, Green, and Co., 1928.

Hamer, W. J. and Wu, Y. C.: Osmotic coefficients and mean activity coefficients of uni-valent electrolytes in water at $25^{\circ} \mathrm{C}$, J. Phys. Chem. Ref. Data, 1, 1047-1099, 1972.

Hänel, G.: The size of atmospheric aerosol particles as a function of the relative humidity, Beitr. Phys. Atmos., 43, 119-132, 1970.
Hänel, G.: The properties of atmospheric aerosol particles as functions of the relative humidity at thermodynamic equilibrium with the surrounding moist air, Adv. Geophys. Res., 19, 73-188, 1976.

Heyrovska, R.: A Reappraisal of Arrhenius' Theory of Partial Dissociation of Electrolytes, American Chem. Soc., 1989.

Hofmeister, F.: Zur Lehre von der Wirkung der Salze, Arch. Exp. Pathol. Pharmakol, (Leipzig) 24 (1888) 247-260; translated in: Zur Lehre von der Wirkung der Salze (about the science of the effect of salts: Franz Hofmeister's historical papers, edited by: Kunz, W., Henle, J., and Ninham, B. W., Curr. Opin. Coll. Interface Sci., 9, 19-37, 2004.

Holgate, S. T., Samet, J. M., Koren, H. S., and Maynard, R. L.: Air pollution and health, Academic Press, San Diego, 1999.

Intergovernmental Panel on Climate Change (IPCC): Climate Change 2007: The Physical Science Basis, Contribution of Working Group I to the Fourth Assessment Report of the Intergovernmental Panel on Climate Change, edited by: Solomon, S., Qin, D., Manning, M., Chen, Z., Marquis, M., Averyt, K. B., Tignor, M., and Miller, H. L., Cambridge University Press, Cambridge, UK and New York, NY, USA, 2007.

IUPAC Solubility Data Series, International Union of Pure and Applied Chemistry, Vol. 1 to 53 were published by Pergamon Press, Oxford, from 1979 to 1994; subsequent volumes were published by Oxford University Press, Oxford.

Jöckel, P., Tost, H., Pozzer, A., Brühl, C., Buchholz, J., Ganzeveld, L., Hoor, P., Kerkweg, A., Lawrence, M. G., Sander, R., Steil, B., Stiller, G., Tanarhte, M., Taraborrelli, D., van Aardenne, J., and Lelieveld, J.: The atmospheric chemistry general circulation model ECHAM5/MESSy1: consistent simulation of ozone from the surface to the mesosphere, Atmos. Chem. Phys., 6, 50675104, 2006, http://www.atmos-chem-phys.net/6/5067/2006/.

Kim, Y. P., Seinfeld, J. H., and Saxena, P.: Atmospheric gas/aerosol equilibrium I. Thermodynamic model, Aerosol Sci. Technol., 19, 157-181, 1993a.

Kim, Y. P., Seinfeld, J. H., and Saxena, P.: Atmospheric gas/aerosol equilibrium II. Analysis of common approximations and activity coefficient calculation methods, Aerosol Sci. Technol., 19, 182198, 1993b.

Kim, Y. P. and Seinfeld, J. H.: Atmospheric gas/aerosol equilibrium III. Thermodynamics of crustal elements $\mathrm{Ca}^{2+}, \mathrm{K}^{+}$, and $\mathrm{Mg}^{2+}$, Aerosol Sci. Technol., 22, 93-110, 1995.

Köhler, H.: The nucleus in and the growth of hygroscopic droplets, Trans. Faraday Soc., 32, 1152-1162, 1936.

Lelieveld, J., Berresheim, H., Borrmann, S., Crutzen, P. J., Dentener, F. J., Fischer, H., Feichter, J., Flatau, P. J., Heland, J., Holzinger, R., Korrmann, R., Lawrence, M. G., Levin, Z., Markowicz, K. M., Mihalopoulos, N., Minikin, A., Ramanathan, V., de Reus, M., Roelofs, G. J., Scheeren, H. A., Sciare, J., Schlager, H., Schultz, M., Siegmund, P., Steil, B., Stephanou, E. G., Stier, P., Traub, M., Warneke, C., Williams, J., and Ziereis, H.: Global Air Pollution Crossroads over the Mediterranean, Science, 298, 794-799, 2002.

Low, R. D. H.: A generalized equation for the solution effect in droplet growth, Atmos. Sci., 26, 608-611, 1969.

Meng, Z., Seinfeld, J. H., Saxena, P., and Kim, Y. P.: Atmospheric gas/aerosol equilibrium. IV: Thermodynamics of carbonates, Aerosol Sci. Technol., 131-154, 1995.

Metzger, S. M.: Gas/Aerosol Partitioning: A simplified Method 
for Global Modeling, Ph.D. Thesis, University Utrecht, The Netherlands, ISBN:90-393-2510-3, http://igitur-archive.library. uu.nl/dissertations/1930853/inhoud.htm, 2000.

Metzger, S. M., Dentener, F. J., Lelieveld, J., and Pandis, S. N.: Gas/aerosol partitioning I: A computationally efficient model, J. Geophys. Res., 107(D16), ACH 16-1-24, doi:10.1029/2001JD001102, 2002.

Metzger, S., Mihalopoulos, N., and Lelieveld, J.: Importance of mineral cations and organics in gas-aerosol partitioning of reactive nitrogen compounds: case study based on MINOS results, Atmos. Chem. Phys., 6, 2549-2567, 2006, http://www.atmos-chem-phys.net/6/2549/2006/.

Mozurkewich M.: The dissociation constant of ammonium nitrate and its dependence on temperature, relative humidity and particle size, Atmos. Environ., 27A, 261-270, 1993.

Nenes, A., Pilinis, C., and Pandis, S. N.: Isorropia: A new thermodynamic model for multiphase multicomponent inorganic aerosols, Aquat. Geochem., 4, 123-152, 1998.

Nernst, W.: Z. Phys. Chem., 4, 129, 1889.

Pilinis, C., Pandis, S. N., and Seinfeld, J. H.: Sensitivity of direct climate forcing by atmospheric aerosols to aerosol size and composition, J. Geophys. Res., 100, 18 739-18 754, 1995.

Pfeffer, W.: Pflanzenphysiologie, Leipzig, Verlag von W. Engelmann, 1881.

Pruppacher, H. R. and Klett, J. D.: Microphysics of Clouds and Precipitation, Dordrecht, Holland, D. Reidel Publ. Co., 950 p., 1997.

Raoult, F. M.: Z. Phys. Chem., 2, 353, 1888.

Robinson, R. A. and Stokes, R. H.: Electrolyte solutions, 2nd Ed., Butterworths, London, 1965.

Röckner, E., Bäuml, G., Bonaventura, L., Brokopf, R., Esch, M., Giorgetta, M., Hagemann, S., Kirchner, I., Kornblueh, L., Manzini, E., Rhodin, A., Schlese, U., Schulzweida, U., and Tompkins, A.: The atmospheric general circulation model ECHAM5. PART I: Model description, Max Planck Institute for Meteorology, MPI-Report 349, http://www.mpimet.mpg.de/ fileadmin/publikationen/Reports/maxscirep349.pdf, 2003.
Seinfeld, J. H. and Pandis, S. N.: Atmospheric chemistry and physics, J. Wiley and Sons, Inc., New York, 1998.

Stokes, R. H. and Robinson, R. A.: Interactions in aqueous nonelectrolyte solutions. I. Solute solvent equilibria, J. Phys. Chem., 70, 2126-2130, 1966.

Tang, I. N. and Munkelwitz, H. R.: Water activities, densities, and refractive indices of aqueous sulfates and sodium nitrate droplets of atmospheric importance, J. Geophys. Res., 99, 18 801-18 808, 1994.

ten Brink, H. M., Veefkind, J. P., Waijers-Ijpelaan, A., and van der Hage, J. C.: Aerosol light-scattering in The Netherlands, Atmos. Environ., 30, 4251-4261, 1996.

van't Hoff, J. H.: Die Rolle des osmotischen Druckes in der Analogie zwischen Lösungen und Gasen, Z. Phys. Chem., 1, 481, 1887.

Vignati E., Wilson, J., and Stier, P.: M7: An efficient size-resolved aerosol microphysics module for large-scale aerosol transport models, J. Geophys. Res., 109, D22202, doi:10.1029/2003JD004485, 2004.

Warneck, P.: Chemistry of the Natural Atmosphere, Internat. Geophys. Series, 41, Academic Press. Inc., 1988.

Winkler, P.: The growth of atmospheric aerosol particles as a function of the relative humidity - II. An Improved concept of mixed nucleii, Aerosol Sci., 4, 373-387, 1973.

Winkler, P.: The growth of aerosol particles with relative humidity, Physica Scripta, 37, 223-230, 1988.

Wexler, A. S. and Potukuchi, S.: Kinetics and Thermodynamics of Tropospheric Aerosols, Atmospheric Particles, John Wiley \& Sons Ltd., 1998.

Zadanovskii, A. B.: New methods of calculating solubilities of electrolytes in multicomponent systems, Zhu. Fiz. Khim., 22, 14751485, 1948.

Zaveri, R. A., Easter, R. C., and Wexler, A. S.: A new method for multicomponent activity coefficients of electrolytes in aqueous atmospheric aerosols, J. Geophys. Res.-Atmos., 110, D02201, doi:10.1029/2004JD004681, 2005. 